\title{
A penalty function approach to occasionally binding credit constraints*
}

\author{
Michał Brzoza-Brzezina ${ }^{\dagger} \quad$ Marcin Kolasa $^{\ddagger} \quad$ Krzysztof Makarski $^{\S}$
}

\begin{abstract}
Occasionally binding credit constraints (OBC) have recently been explored as a promising way of modeling financial frictions. However, given their highly non-linear nature, most of the literature has concentrated on small models that can be solved using global methods. In this paper, we investigate the workings of OBC introduced via a smooth penalty function. This allows us to move towards richer models that can be used for policy analysis. We show that in a deterministic setting the $\mathrm{OBC}$ approach delivers welcome features, like asymmetry and non-linearity in reaction to shocks. However, feasible local approximations, necessary to generate stochastic simulations, suffer from fatal shortcomings that make their practical application questionable.
\end{abstract}

$J E L:$ E30, E44

Keywords: financial frictions, DSGE models, occasionally binding constraints, penalty function

${ }^{*}$ This project was financed by the National Science Centre grant No. 2012/05/B/HS4/04158. The views expressed herein are those of the authors and not necessarily those of the National Bank of Poland or the Warsaw School of Economics. We would like to thank Łukasz Drozd, Tom Holden, Matteo Iacoviello, Giovanni Lombardo, Jaromir Nosal and an anonymous referee for helpful suggestions and discussions. This paper benefited also from comments received at the 18th CEF conference in Prague, 2012 WIEM in Warsaw, 8th Dynare conference in Zurich, 44th MMF conference in Dublin, 21st Annual Symposium of the SNDE in Milan, 2nd FMND in Paris, 2015 EcoMod Conference in Boston and seminar at the National Bank of Poland.

${ }^{\dagger}$ National Bank of Poland and Warsaw School of Economics; Email: michal.brzoza-brzezina@nbp.pl.

${ }^{\ddagger}$ Corresponding author; National Bank of Poland and Warsaw School of Economics; ul. Świętokrzyska 11/21, 00-919 Warsaw, Poland; Email: marcin.kolasa@nbp.pl.

$\S$ National Bank of Poland and Warsaw School of Economics; Email: krzysztof.makarski@nbp.pl. 


\section{Introduction}

Dynamic, stochastic general equilibrium (DSGE) models featuring financial frictions have recently become highly popular both at central banks and in the academic world. Their applications range from explaining the role of financial shocks during the crisis (Gerali et al., 2010; Iacoviello and Neri, 2010; Brzoza-Brzezina and Makarski, 2011), through analyzing optimal monetary policy in the presence of financial frictions (Cúrdia and Woodford, 2008; De Fiore and Tristani, 2013; Carlstrom et al. (2010); Kolasa and Lombardo, 2014) to the impact of macroprudential regulations on the economy (Angeloni and Faia, 2013; Meh and Moran, 2010; Aliaga-Díaz and Olivero, 2012).

A substantial part of the literature features financial frictions in the form of credit constraints. In this concept, that can be traced back to the seminal paper of Kiyotaki and Moore (1997), some agents (entrepreneurs or households) are limited in their borrowing capacity by the amount of collateral that they can provide to the lender. The constraint is assumed to be eternally binding, which facilitates the model solution as standard perturbation techniques can be applied. A number of papers followed Iacoviello (2005) and used this approach to model frictions in the housing market. However, while conceptually and computationally attractive, the eternally binding constraint (EBC) setup suffers from a major shortcoming. As documented by Brzoza-Brzezina et al. (2013), the permanent nature of collateral constraints generates strong, short-lived and symmetric reactions of macroeconomic variables to shocks. This means in particular that the EBC modeling strategy does not allow to distinguish between "normal" and "stress" periods.

This model feature seems inconsistent with empirical evidence. Table 1 presents the skewness (i.e. the third standardized moment) for main variables related to the housing market. The reason for looking at this part of the economy is its important role in driving the business cycle as identified in the financial frictions literature (see e.g. Iacoviello and Neri, 2010). It is clear that residential investment, housing stock, change in mortgage loans and house price inflation are all skewed downwards, i.e. left tail events are relatively more frequent. This suggests either that shocks affecting the housing market are asymmetric, or that it responds to symmetric shocks in a skewed fashion.

In this paper we follow the second option by considering a model in which asymmetries 
emerge endogenously from constraints facing the agents. ${ }^{1}$ Such an approach has not only a more structural flavor, but also seems to be supported by some recent empirical literature. In particular, Hubrich and Tetlow (2012) show that negative output effects of financial shocks are much more pronounced and long-lasting in times of high financial stress than in normal times. Kaufmann and Valderrama (2010) show that amplifying effects of loan shocks work in a highly nonlinear fashion. They identify periods during which loan shocks have only moderate effect on GDP and periods when they strongly amplify the cycle.

Collateral constraints are certainly important in real life and potentially useful for modeling purposes. However, the discussion presented above suggests that they should not be applied in a permanently and symmetrically binding fashion. A preferred specification would feature constraints that do not matter under normal circumstances (from the modeling perspective: in the vicinity of the steady state), but become binding occasionally, i.e. during episodes of unfavorable economic conditions (e.g. after a series of negative macroeconomic or financial shocks).

The idea of occasionally binding constraints (OBC) is not new (e.g. Christiano and Fisher, 2000; Mendoza, 2010; Brunnermeier and Sannikov, 2014). However, given their highly non-linear nature, they should ideally be solved with global methods. Due to the curse of dimensionality, however, these can be applied only to relatively small models with a limited number of state variables. In spite of the progress achieved in the area of global solution techniques in recent years, such methods are still out of range for models of the size used for practical policymaking, i.e. featuring a number of real and nominal rigidities. For instance, Fernández-Villaverde et al. (2012) use collocation methods to solve a New Keynesian model at the zero lower bound. However, their model features only five state variables. Adding standard features of models currently used at central banks like endogenous capital, habit formation, wage rigidity, interest rate inertia or indexation (Christiano et al., 2005; Smets and Wouters, 2003) would more than triple the number of state variables, making a global solution impossible to obtain in reasonable time. At the same time, adding these frictions

\footnotetext{
${ }^{1}$ In terms of methodological approach, this paper is hence related to the literature investigating asymmetries arising from downward nominal rigidities (see e.g. Kim and Ruge-Murcia, 2009; Fahr and Smets, 2010) or the zero lower bound on nominal interest rates (Eggertsson and Woodford, 2004; Adam and Billi, 2006). The alternative approach, i.e. generating skewness by feeding skewed shocks into a linearized model, is followed e.g. by Grabek et al. (2011).
} 
seems indispensable when the models are to be applied for instance for analyzing business cycle consequences of macroprudential policies. For such models, local solution methods are still the only feasible option.

For these reasons, we thoroughly investigate a potentially attractive shortcut to approximate occasionally binding constraints that has been introduced by Luenberger (1973) and Judd (1998), and more recently advocated by De Wind (2008), i.e. the so-called barrier or penalty function method. This approach essentially consists in converting inequality constraints into equality constraints, making the use of standard perturbation techniques possible. It has been applied to a range of medium-sized macroeconomic models e.g. by Rotemberg and Woodford (1999), Preston and Roca (2007) and Kim et al. (2010). ${ }^{2}$ To this end, we construct a DSGE model with a standard set of rigidities and collateral constraints in the spirit of Iacoviello (2005), except that the latter are introduced in the form of a smooth penalty function. We parametrize the model in such a way that the constraint does not play an important role close to the steady state, but becomes binding when the economy is hit by sufficiently large negative shocks. Next, we investigate the main features of the model both under perfect foresight and in a stochastic setting using its local approximations of various orders.

Our main findings are as follows. First, the introduction of occasionally binding constraints via the penalty function approach allows to generate asymmetric and non-linear reactions of the economy to shocks. Second, this feature can be also reproduced for local approximations, though only for orders higher than two. Third, and less optimistic, stochastic simulations for 2nd, 3rd and 4th order approximations suffer from serious stability problems that make them inapplicable in practice. This finding stands in contrast to De Wind (2008), who shows that for a simple model with a penalty function higher order perturbation can be a feasible solution method. We show that this result does not translate into more sophisticated models. Approximations of order higher than four are, on the other hand, prohibitively expensive in terms of storing and computing power for medium-sized business

\footnotetext{
${ }^{2}$ An alternative approach that has been recently proposed to tackle occasionally binding constraints is the piecewise-linear perturbation method of Guerrieri and Iacoviello (2015). This method is attractive because it can be easily applied to models with many state variables. However, in contrast to the penalty function method, it ignores the precautionary motives that are linked to the possibility of hitting the constraint. As a result, the piecewise-linear method cannot be used to evaluate welfare implications of alternative stabilization policies.
} 
cycle models. Moreover, even when simulations can be kept stable, the approximated shape of the penalty function is frequently inconsistent with its assumed functional form (e.g. it becomes close to parabolic for even order approximations). All in all, while being practical for non-stochastic models, the penalty function approach unfortunately fails to fulfill our expectations in a stochastic environment. This makes it an attractive way of introducing financial frictions into deterministic models like GEM (Tchakarov et al., 2004) or EAGLE (Gomes et al., 2012). However, a fully fledged application in a realistic stochastic framework seems currently out of range.

The rest of the paper is structured as follows. In Sections 2 and 3 we present the model and its calibration. Section 4 uses deterministic simulations to present the model's features. In section 5 we investigate the performance of local approximations and their usefulness in generating stochastic simulations. Section 6 concludes.

\section{$2 \quad$ Model}

We consider a closed economy DSGE model in the spirit of Iacoviello (2005), where some agents face collateral constraints on their borrowing. In this section we first sketch out the structure of the model and then present two alternative specifications of the credit constraint, i.e. the $\mathrm{EBC}$ and $\mathrm{OBC}$ variants.

\subsection{Households}

There are two types of households indexed by $\iota$ on a unit interval: patient of measure $\omega_{P}$ and impatient of measure $\omega_{I}=1-\omega_{P} .^{3}$

\subsubsection{Patient households}

In each period, patient households decide on their consumption of goods $c_{P, t}$ and housing services $\chi_{P, t}$, labor supply $n_{P, t}$, capital stock $k_{t}$ and savings deposits in the banking sector $D_{t}{ }^{4}$

\footnotetext{
${ }^{3}$ We employ the following notational convention: all variables denoted with superscript $P$ or $I$ are expressed per patient or impatient household, respectively, while all other variables are expressed per all households. For example, $k_{t}$ denotes per capita capital and since only patient households own capital, capital per patient households is equal to $k_{P, t}=k_{t} / \omega_{P}$.

${ }^{4}$ We calibrate the model so that patient households save and never borrow. Therefore, to simplify notation, we eliminate credits (which they would not take anyway) from their budget constraint. Similarly, we eliminate
} 
There are no financial frictions on the depositors' side and hence patient households can save at the policy (interbank) rate $R_{t}$. They are also assumed to own all firms and banks in the economy, which pay them dividends $\Pi_{P, t}$.

Households maximize the following lifetime utility function (with external habit formation in consumption and housing)

$$
E_{0}\left\{\sum_{t=0}^{\infty} \beta_{P}^{t}\left[\frac{\left(c_{P, t}(\iota)-\xi_{c} c_{P, t-1}\right)^{1-\sigma_{c}}}{1-\sigma_{c}}+A_{\chi} \frac{\left(\chi_{P, t}(\iota)-\xi_{\chi} \chi_{P, t-1}\right)^{1-\sigma_{\chi}}}{1-\sigma_{\chi}}-A_{n} \frac{n_{P, t}(\iota)^{1+\sigma_{n}}}{1+\sigma_{n}}\right]\right\}
$$

subject to the budget constraint

$$
\begin{array}{r}
P_{t} c_{P, t}(\iota)+P_{\chi, t}\left(\chi_{P, t}(\iota)-\left(1-\delta_{\chi}\right) \chi_{P, t-1}(\iota)\right)+P_{k, t}\left(k_{P, t}(\iota)-\left(1-\delta_{k}\right) k_{P, t-1}(\iota)\right)+D_{t}(\iota) \leq \\
\leq W_{P, t} n_{P, t}(\iota)+R_{k, t} k_{P, t-1}(\iota)+R_{t-1} D_{t-1}(\iota)+\Pi_{P, t}
\end{array}
$$

where $P_{t}$ denotes the price of consumption goods, $P_{\chi, t}$ is the price of housing, $P_{k, t}$ is the price of capital, $W_{P, t}$ stands for patient households' nominal wage, while $R_{k, t}$ is the rental rate on capital.

\subsubsection{Impatient households}

Impatient households choose in each period the level of consumption $c_{I, t}$ and housing services $\chi_{I, t}$, as well as labor supply $n_{I, t}$. Furthermore, we assume that impatient households can take differentiated loans from banks of measure one, which they aggregate according to the following formula

$$
L_{I, t}(\iota)=\left[\int_{0}^{1} L_{I, t}(\iota, j)^{\frac{1}{\mu_{L}}} d j\right]^{\mu_{L}}
$$

where $L_{I, t}(\iota, j)$ denotes a loan taken by household $\iota$ from bank $j$. This specification gives rise to the following definition of the interest rate on loans $R_{L, t}$

$$
R_{L, t}=\left[\int_{0}^{1} R_{L, t}(j)^{\frac{1}{1-\mu_{L}}}\right]^{1-\mu_{L}}
$$

deposits from impatient households' budget constraint (6). 
where $R_{L, t}(j)$ denotes the interest rate charged by bank $j$.

Impatient households maximize the following lifetime utility function

$$
E_{0}\left\{\sum_{t=0}^{\infty} \beta_{I}^{t}\left[\frac{\left(c_{I, t}(\iota)-\xi_{c} c_{I, t-1}\right)^{1-\sigma_{c}}}{1-\sigma_{c}}+A_{\chi} \frac{\left(\chi_{I, t}(\iota)-\xi_{\chi} \chi_{I, t-1}\right)^{1-\sigma_{\chi}}}{1-\sigma_{\chi}}-A_{n} \frac{n_{I, t}(\iota)^{1+\sigma_{n}}}{1+\sigma_{n}}\right]\right\}
$$

subject to the budget constraint

$$
\begin{aligned}
P_{t} c_{I, t}(\iota)+P_{\chi, t}\left(\chi_{I, t}(\iota)-\left(1-\delta_{\chi}\right) \chi_{I, t-1}(\iota)\right)+\int_{0}^{1} R_{L, t-1}(j) L_{I, t-1}(\iota, j) d j \leq & \\
& \leq W_{I, t} n_{I, t}(\iota)+L_{I, t}(\iota)
\end{aligned}
$$

the formula for loans (3) and the collateral constraint

$$
R_{L, t} L_{I, t}(\iota) \leq m_{\chi, t} E_{t}\left\{P_{\chi, t+1}\right\}\left(1-\delta_{\chi}\right) \chi_{I, t}(\iota)
$$

where $W_{I, t}$ denotes the impatient households' nominal wage and $m_{\chi, t}$ is a loan-to-value (LTV) shock that follows an $\operatorname{AR}(1)$ process with a mean $m_{\chi}$, persistence $\rho_{m}$ and a standard deviation of innovations $\sigma_{m}$.

\subsubsection{Labor market}

Both patient and impatient households offer differentiated labor services. Each household supplies monopolistically distinct labor services to competitive aggregators, who transform them into homogenous labor input according to the following formula

$$
n_{t}=\left[\omega_{P}\left(n_{t}^{P}\right)^{\frac{1}{\mu_{n}}}+\left(1-\omega_{P}\right)\left(n_{t}^{I}\right)^{\frac{1}{\mu_{n}}}\right]^{\mu_{n}}
$$

where

$$
\begin{aligned}
n_{P, t} & =\left[\frac{1}{\omega_{P}} \int_{0}^{\omega_{P}} n_{P, t}(\iota)^{\frac{1}{\mu_{w}}} d \iota\right]^{\mu_{w}} \\
n_{I, t} & =\left[\frac{1}{\omega_{I}} \int_{0}^{\omega_{I}} n_{I, t}(\iota)^{\frac{1}{\mu_{w}}} d \iota\right]^{\mu_{w}}
\end{aligned}
$$

We assume that households set their nominal wages $W_{P, t}$ and $W_{I, t}$ according to the 
Calvo scheme. In each period, each household with probability $\left(1-\theta_{w}\right)$ receives a signal to reoptimize its nominal wage. Otherwise, wages are indexed according to $\pi_{\zeta_{w}, t}=\zeta_{w} \pi_{t-1}+$ $\left(1-\zeta_{w}\right) \pi$ where $\pi_{t} \equiv P_{t} / P_{t-1}$ and $\pi$ denote, respectively, inflation and its steady state value.

We assume perfect risk sharing across households of the same type. As a result, wage stickiness does not create additional heterogeneity in consumption and housing choices between the agents.

\subsection{Producers}

In our model economy there are several types of firms, all owned by patient households and hence using their marginal utility as a discount factor. Producers of differentiated intermediate goods operate in a monopolistically competitive environment and sell their goods to final goods producers who aggregate them into final goods. The final goods are next either consumed or purchased by capital and housing producers, who combine them with the existing capital and housing stocks, and resell to households.

\subsubsection{Capital and housing producers}

In each period, perfectly competitive capital and housing goods producers purchase undepreciated capital and housing stocks from the previous period and produce new capital and housing according to the following formulas

$$
k_{t}=(1-\delta) k_{t-1}+\left(1-S_{k}\left(\frac{i_{k, t}}{i_{k, t-1}}\right)\right) i_{k, t}
$$

and

$$
\chi_{t}=(1-\delta) \chi_{t-1}+\left(1-S_{\chi}\left(\frac{i_{\chi, t}}{i_{\chi, t-1}}\right)\right) i_{\chi, t}
$$

where $i_{k, t}$ and $i_{\chi, t}$ denote, respectively, capital and housing investment. We assume that

$S_{k}\left(\frac{i_{k, t}}{i_{k, t-1}}\right)=\frac{\kappa_{k}}{2}\left(\frac{i_{k, t}}{i_{k, t-1}}-1\right)^{2}$ and $S_{\chi}\left(\frac{i_{\chi, t}}{i_{\chi, t-1}}\right)=\frac{\kappa_{k}}{2}\left(\frac{i_{\chi, t}}{i_{\chi, t-1}}-1\right)^{2}$.

\subsubsection{Final goods producers}

Final goods producers operate in a competitive setting. They purchase differentiated intermediate goods $y_{t}(i)$ of measure one and aggregate them into final good $y_{t}$ according to the 
following technology

$$
y_{t}=\left(\int y_{t}(i)^{\frac{1}{\mu}} d i\right)^{\mu}
$$

\subsubsection{Intermediate goods producers}

Intermediate goods producers, indexed by $i$, combine labor and capital with the following technology

$$
y_{t}(i)=z_{t} k_{t}(i)^{\alpha} n_{t}(i)^{1-\alpha}
$$

where $z_{t}$ denotes productivity shock that follows an $\operatorname{AR}(1)$ process with persistence $\rho_{z}$ and a standard deviation of innovations $\sigma_{z}$. They operate in a monopolistically competitive environment and set their prices according to the Calvo scheme. In each period, each producer $i$ with probability $(1-\theta)$ receives a signal to reoptimize its price. Otherwise, prices are indexed according to $\pi_{\zeta, t}=\zeta \pi_{t-1}+(1-\zeta) \pi$.

\subsection{Closing the model}

\subsubsection{Financial intermediation}

In our economy there are no frictions between deposits and the interbank market, so patient households earn the policy (interbank) rate on their deposits. However, the lending rate and the interbank rate are different. This is due to the presence of a continuum of monopolistically competitive lending banks which borrow in the interbank market at the policy rate to finance differentiated loans extended to households at the lending rate $R_{L, t}(j)$. By solving the banks' problem subject to the demand for loans from impatient households, we get the following equilibrium relation between the lending rate and the policy rate

$$
R_{L, t}=\mu_{L} R_{t}
$$

\subsubsection{Monetary policy}

The monetary authority sets the policy rate according to the standard Taylor rule

$$
\frac{R_{t}}{R}=\left(\frac{R_{t-1}}{R}\right)^{\gamma_{R}}\left[\left(\frac{\pi_{t}}{\pi}\right)^{\gamma_{\pi}}\left(\frac{y_{t}}{y}\right)^{\gamma_{y}}\right]^{1-\gamma_{R}} e^{\varepsilon_{R, t}}
$$


where variables without time subscripts denote their steady state values and $\varepsilon_{R, t}$ is a monetary policy shock with a standard deviation $\sigma_{R}$.

\subsubsection{Market clearing}

We impose a standard set of market clearing conditions. In particular, housing market clearing implies

$$
\omega_{P} \chi_{P, t}+\omega_{I} \chi_{I, t}=\chi_{t}
$$

and the aggregate resource constraint is

$$
y_{t}=c_{t}+i_{k, t}+i_{\chi, t}
$$

\subsection{Occasionally and eternally binding credit constraints}

A standard way of dealing with the inequality constraint (7) is to assume that it is eternally binding. This is legitimate if impatient households' discount factor is low and shocks hitting the economy are sufficiently small. Hence, if we define the Lagrange multiplier on the collateral constraint as $\Theta_{t} / R_{L, t}$, the EBC variant results in the following Euler equation

$$
u_{I, c, t}=E_{t}\left\{\beta_{I} u_{I, c, t+1} \pi_{t+1}^{-1}\right\} R_{L, t}+\Theta_{t}
$$

where $u_{I, c, t}$ denotes impatient agents' marginal utility of consumption.

While solving the problem with occasionally binding credit constraints (OCB), we follow De Wind (2008) and approximate the inequality constraint (7) by a smooth penalty function

$$
\Psi_{t}=\frac{1}{\eta} \exp \left[\eta \Gamma_{t}\right]
$$

where $\Gamma_{t} \equiv E_{t}\left\{R_{L, t} l_{I, t}-m_{\chi, t} p_{\chi, t+1} \pi_{t+1}\left(1-\delta_{\chi}\right) \chi_{I, t}\right\}, l_{I, t} \equiv L_{I, t} / P_{t}$ and $p_{\chi, t} \equiv P_{\chi, t} / P_{t}$. The derivative of this penalty function with respect to $l_{I, t}$, which we will refer to as the penalty function slope, is equal to

$$
\Psi_{l, t}=R_{L, t} \exp \left[\eta \Gamma_{t}\right]
$$


and the Euler equation becomes

$$
u_{I, c, t}=E_{t}\left\{\beta_{I} u_{I, c, t+1} \pi_{t+1}^{-1}\right\} R_{L, t}+\Psi_{l, t}
$$

Therefore, depending on the setting, financial frictions manifest themselves in either $\Theta_{t}$

or $\Psi_{l, t}$. One of the problems with the $\mathrm{EBC}$ variant is that $\Theta_{t}$ can go negative (i.e. the assumption on the eternally binding nature of the constraint is violated) in simulations with sufficiently strong credit easing. This setup also produces very little asymmetry between responses to positive and negative shocks. In contrast, since $\Psi_{l, t}$ is increasing and convex in $\Gamma_{t}$, the $\mathrm{OBC}$ variant will generate asymmetric responses to changes in credit conditions. In particular, if $\eta \rightarrow \infty$, the penalty function collapses to the inequality constraint, i.e. exogenous credit easing (tightening) will have no (very strong) effect on the economy.

\section{Calibration}

We calibrate the model to the US economy. The time frequency is quarterly. The exact values of the calibrated parameters are presented in Table 3.

We take most of the parameters from the literature. The discount factor for patient households is set to 0.99, which is a standard value for quarterly data. We choose the annual depreciation rate for capital and housing of $8 \%$ and $3.5 \%$, respectively. The inverse of the intertemporal elasticity of substitution in consumption and housing, as well as the inverse of the Frisch elasticity of labor supply are all set to 2, as it is common in the macro literature. We calibrate the degree of external habit formation both in consumption and housing at 0.7 . The Calvo parameters for wages and prices are set to 0.75 , while the respective indexation parameters are assumed to be 0.5. We choose the same markups in the labor and product markets of 1.2 , which is in line with the literature. The elasticity of substitution between labor of patient and impatient households is calibrated at 6. Following Christiano et al. (2005), we choose the capital adjustment cost curvature parameter equal to 5 and, since the process of housing accumulation seems to be of a similar nature, we parametrize housing adjustment costs in the same way. For the Taylor rule, we assume a standard set of parameters, i.e. interest rate smoothing $\gamma_{R}$ equal to 0.9 , the inflation coefficient $\gamma_{\pi}$ of 1.5 
and the output coefficient $\gamma_{y}$ equal to 0.5 . The steady state annual inflation rate is set to $2 \%$.

There are several parameters that are calibrated to match some key steady state ratios, summarized in Table 2. In particular, we set the housing weight in utility to match the residential investment share in GDP, the capital elasticity of output to match the physical capital investment share in GDP, the labor weight in utility to match the steady state hours, the share of impatient households to match the share of loans in GDP, and the markup in financial intermediation to match the spread between the lending rate and the policy rate. Finally, the steady state LTV ratio is set to $75 \%$.

A crucial part of our calibration concerns parametrization of the penalty function. Ideally, we would like to make it as steep as possible (i.e. set $\eta$ to a large number) since that brings us closer to the original non-equality constraint given by equation (7). However, as discussed by De Wind (2008), there is a trade-off between the amount of penalty function curvature and feasibility of solving the model using perturbation techniques. Since one of our goals is to investigate the ability of the $\mathrm{OBC}$ framework to generate reasonable stochastic simulations (which, given the model size, requires low order approximations), we opt for a moderate value of $\eta=50$.

The workings of the OBC framework depend not only on the overall curvature of the penalty function, but also on how the penalty function responds to changes in leverage in normal times. It can be shown that, given the calibration choices discussed above, the steady state slope of the penalty function $\Psi_{l}$ is controlled by the impatient households' discount factor. To see it, it is instructive to look at equation (22) evaluated in the steady state:

$$
\Psi_{l}=u_{I, c}\left(1-\beta_{I} \frac{R_{\chi}}{\pi}\right)=u_{I, c}\left(1-\beta_{I} \frac{\mu_{L}}{\beta_{P}}\right)
$$

where the second equality follows from patient households' Euler equation and the solution to financial intermediaries' problem given by equation (15).

Hence, if we want the credit constraint to be literally not binding in normal times, the penalty function should be perfectly flat in the vicinity of the steady state, which can be achieved by setting the impatient households' discount factor close to its upper bound of $\beta_{P} \mu_{L}^{-1}$. However, since the penalty function is strictly positive and increasing in leverage, 
low $\Psi_{l}$ also implies that the steady state leverage will be far from the one at which the constraint starts binding. We solve this trade-off by allowing the collateral constraint to be moderately binding in the steady state. More precisely, we set $\beta_{I}$ to 0.985 , which translates into a difference between impatient households' subjective rate of time preference $\beta_{I}^{-1}$ and the steady state real lending rate $R_{\chi} \pi^{-1}$ of $50 \mathrm{bp}$ (annualized). This parametrization also implies the steady state leverage ratio (repayment value of loans over the expected value of accepted collateral) equal to $74 \%$, i.e. 1 pp. below the LTV ratio.

In the simulation exercises discussed in the next section we use three shocks, all of which are calibrated outside of the model. The productivity shock is calibrated similarly to Cooley and Prescott (1995), while the monetary shock parametrization comes from Smets and Wouters (2007). The LTV shock process is estimated using the data on the loan to price ratio reported by the Federal Housing Finance Agency in its Monthly Interest Rate Survey.

\section{Non-approximated solution}

In this section we discuss the workings of the OBC framework using a selection of deterministic (i.e. perfect foresight) simulations generated from the model laid out above. In such a non-stochastic environment one does not need to rely on any approximation of the decision rules implied by the model. This allows us to fully assess the degree of non-linearities and asymmetries embedded in the model due to the presence of the penalty function. ${ }^{5}$

\subsection{The mechanics of occasionally binding constraints}

We start by demonstrating how parametrization of the model, and the penalty function in particular, affects the workings of the OBC setup. As mentioned in the previous section, there are two key parameters in this respect: the impatient households' discount factor $\beta_{I}$ and the penalty function curvature $\eta$.

We first examine how the model dynamics is affected by $\beta_{I}$, holding the the penalty function curvature $\eta$ as in our baseline calibration. As discussed in the previous section, the

\footnotetext{
${ }^{5}$ All model simulations are performed using Dynare and Dynare++. See Adjemian et al. (2011).
} 
higher $\beta_{I}$, the flatter the penalty function in the steady state, i.e. the further the steady state equilibrium from the steep part of the penalty function. Consequently, for a given degree of curvature $\eta$, large $\beta_{I}$ implies little effect of small changes in LTV around the steady state on credit conditions. This effect is illustrated in Figure 1. If the inverse of $\beta_{I}$ almost equals the long-run real interest rate paid on loans, a fall in LTV (starting from the steady state) has virtually no effect on other variables. Decreasing this parameter implies moving up along the penalty function. Since $\Psi_{l, t}$ is increasing and convex, it responds much more if the simulation starts at higher leverage.

We use an analogous set of simulations to highlight the role of the penalty function curvature, holding $\beta_{I}$ as in our baseline calibration. In Figure 2 we compare three alternative calibrations of OBC to the eternally binding benchmark. The OBC setups generate declines in loans that are far more moderate and hence more consistent with the volatility of mortgage loans observed in the data. ${ }^{6}$ Also, the reactions are much smoother, often displaying humpshaped patterns. ${ }^{7}$ If the collateral constraint binds at all times, the inertia in responses is substantially subdued and for some variables (output, consumption, loans) the strongest reaction occurs on impact.

Again, these differences can be traced back to the response of the penalty function slope ( $\Psi_{l, t}$ for $\left.\mathrm{OBC}\right)$ or the normalized Lagrange multiplier on the constraint $\left(\Theta_{t}\right.$ for EBC) as both measure the tightness of credit conditions. Naturally, the steeper the penalty function (i.e. the higher $\eta$ ), the more similar the responses under the two model versions. However, even for $\eta=100$, i.e. a relatively big curvature, the increase in the constraint's tightness is more than four times smaller under OCB than under EBC, which translates into a more muted and inertial contraction in loans in the former variant.

\footnotetext{
${ }^{6}$ The standard deviation of HP-filtered real mortgage loans in the US over the period of 1950-2010 is below $1 \%$.

${ }^{7}$ The empirical literature gives support to inertia in reaction to financial shocks. For instance, Assenmacher-Wesche and Gerlach (2008) present hump-shaped impulse responses to credit shocks (without identifying whether they originate from demand or supply) from a VAR. Kose et al. (2011) identify credit supply shocks in a FAVAR framework and obtain hump-shaped impulse responses. Gilchrist and Zakrajsek (2012) use a VAR to extract shocks to the excess bond premium, also finding hump-shaped reactions of standard macrovariables.
} 


\subsection{Can the OBC setup generate sizable asymmetries?}

As discussed in the introduction, skewness in housing market indicators is a stylized fact of the US business cycle. Therefore, we next examine to what extent the asymmetry embedded in the $\mathrm{OBC}$ penalty function can generate skewness in the responses of the main macrocategories, and housing market variables in particular.

Naturally, as the exponential function is smooth, we can expect to obtain non-negligible asymmetries only for sufficiently large shocks. This point is illustrated in Figure 3, where we plot positive and negative responses to standard (0.45\%) and large (3\%) LTV shocks. For an LTV shock of a typical magnitude, the effects of a credit tightening are mirror images of the effects of a credit easing. However, if we consider relatively large shifts in the collateral requirements, clear asymmetries emerge, both in terms of size and shape of the impulse responses. The most notable example are mortgage loans, that fall strongly after an LTV tightening and increase only moderately in response to an LTV easing. This asymmetry in impatient agents' borrowing conditions is strong enough to translate into asymmetries in consumption and output. The contraction in residential investment exhibits more persistence than it is the case during expansion. Finally, a large negative LTV shock generates a decline in real house prices that is larger than an increase resulting from an LTV easing of the same magnitude.

Virtually all of these asymmetries can be traced back to the workings of the penalty function. As a result, they will be non-negligible only for shocks that sufficiently affect the credit conditions. As an LTV shock has a direct impact on impatient agents' ability to borrow, its potential to generate sizable asymmetries is relatively large. Productivity shocks affect the credit conditions via their impact on the price of collateral and real value of debt, and hence can generate substantial asymmetry in loans as well. As can be seen in Figure 4, depicting the responses to relatively large (1.5\%, i.e. three standard deviations) productivity shocks, loans fall both in response to positive and negative shocks. In the former case, the reason is the fall in house prices and the Fisher debt deflation effect, which tighten the collateral constraint. In the latter, the credit conditions barely change and the fall in loans is driven by patient agents' consumption smoothing motive, which decreases their demand for deposits and hence the supply of loans available to impatient households. This skewness 
in loans translates into some asymmetry in residential investment and consumption, and hence output.

A similar pattern can be observed for big monetary shocks (Figure 5). Also in this case, loans contract both in response to a monetary easing and tightening. This time, however, the resulting asymmetries in output are relatively small, even though the size of the shock is substantial.

Overall, our experiments demonstrate that the OBC framework offers substantial flexibility in its parametrization. It has the potential to generate responses whose persistence resembles more that found in the empirical literature and to explain the asymmetries observed in the macroeconomic time series, especially those related to the housing market. This will be particularly true if a significant part of business cycle fluctuations is driven by shocks that have significant effects on credit conditions.

\section{$5 \quad$ Local approximations}

The natural next step is to run stochastic simulations. To achieve this we apply standard perturbation methods relying on local approximations of the model around the steady state. In the DSGE literature the most frequent approach is log-linearization. However, given the highly nonlinear shape of the penalty function, a simple 1st order approximation would be clearly counterproductive. It has been recognized in the literature that in such cases one has to rely on higher order expansions. One thing that remains ex ante unclear is which order is most appropriate for our purposes.

The answer to such a question is non-trivial. Naturally, higher order expansions allow to approximate the policy functions in the vicinity of the steady state better than low order ones. However, this may be no longer true if we move away from the steady state, i.e. if we want to analyze the effects of large shocks. Also, it is a well-known fact that non-linear expansions can imply spurious explosive dynamics (Kim et al., 2008).

The literature suggests that the choice of the optimal perturbation order can be modelspecific. Lombardo (2010) demonstrates for a simple stochastic neoclassical growth model that increasing the order of approximation usually helps to stabilize the model, i.e. spurious 
explosiveness becomes less of an issue. Den Haan and De Wind (2012) analyze a simple model with a non-negativity constraint approximated by a penalty function and document that the instability problem gets worse when moving from 2nd to 3rd order perturbation, while higher order approximations are stable but generate large and odd oscillations.

Needless to say, while dealing with larger models, one also needs to take into account the computing time necessary to derive higher order expansions. In our case, already the 5th order approximation is prohibitively time and memory consuming. Therefore, in what follows we present our findings on the workings of the 2nd, 3rd and 4th order perturbations to our model.

\subsection{2nd order approximation}

We begin our investigation with the second order perturbation. It should be mentioned that approximation of this order has been previously applied in the literature to solve and simulate models with occasionally binding credit constraints in the form of penalty functions. Mendicino (2012) considers a real model á la Kiyotaki and Moore (1997) and uses the 2nd order approximation to analyze the response to a moderate positive productivity shock, finding very little difference between the $\mathrm{OBC}$ and $\mathrm{EBC}$ variants. We have demonstrated that this result crucially depends on the shock size and sign, as well as on penalty function parametrization. Abo-Zaid (2012) uses a New Keynesian model with collateral constraint on hiring labor to investigate the optimal level of inflation, documenting skewness in the impulse responses. We will show below that some of this finding can actually be spurious.

We first concentrate on relatively large LTV shocks (i.e. 3\%), since, as discussed in the previous section, they are capable of generating relatively high asymmetry. The impulse responses in the deterministic environment are presented in Figure 6. For comparative reasons, we also show the "true" IRFs from the non-approximated model. The figure also plots the analogous reactions for higher order approximations, which will be discussed later. Focusing on the 2nd order perturbation, its comparison to the non-approximated solution clearly shows a shortcoming of the former. In particular, the penalty function derivative $\Psi_{l, t}$ increases in reaction to both positive and negative shocks, while ideally it should show no response for an increase in the LTV ratio. As a result, for several variables the impulse responses differ substantially from the non-approximated solution, and even generate spurious asymmetry. 
For instance, according to the 2nd order perturbation and unlike the "truth", loans decline in response to both expansionary and contractionary LTV shocks.

To understand why this happens it is useful to investigate the shape of $\Psi_{l, t}$ under the 2 nd order perturbation. To this end, we run a stochastic simulation by drawing 1000 shocks to LTV. Leaving for a moment stability problems aside, we present in Figure 7 the scatterplot of the penalty function slope $\Psi_{l, t}$ against the gap between the repayment value of loans and the expected value of accepted collateral, i.e. the argument of the penalty function $\Gamma_{t}$. The reason for the deviations from the deterministic solution becomes evident - the approximated function is almost symmetric.

Let us now return to the problem of stability of stochastic simulations. As described by Den Haan and De Wind (2012), approximations of exponential penalty functions can lead to instabilities as they generate an additional fixed point, which, if close enough to the model's steady state, can destabilize stochastic simulations even for relatively small shocks. Our simulations based on the 2nd order perturbation suffer exactly from this problem. The reason is the left arm of $\Psi_{l, t}$, where the positive slope of $\Psi_{t}$ generates artificial incentives for impatient households to decrease their debt if it is sufficiently far from the constraint.

The literature has suggested two ways of dealing with such spurious unstable dynamics. One option is to apply the "pruning" procedure advocated by Kim et al. (2008). However, this algorithm turned out to be doing a poor job in approximating the shape of the penalty function in our model. This can be seen in Figure 8, which shows that the plot of $\Psi_{l, t}$ against $\Gamma_{t}$ obtained using "pruning" is very fuzzy. ${ }^{8}$ An alternative option is to follow Aruoba et al. (2006) and just eliminate explosive draws. In our case, this approach was delivering a much clearer picture of the shape of the penalty function, and so was applied both to the simulation presented above and to higher order approximations. ${ }^{9}$

Unfortunately, for larger shocks to LTV or for realistic compositions of various shocks, simulations tend to explode too frequently. In particular, for a mixture of LTV, productivity and monetary policy shocks with standard deviations as given in Table 3, our procedure

\footnotetext{
${ }^{8}$ See Den Haan and De Wind (2012) for a detailed explanation of why pruned perturbations can deliver a poor fit even to standard polynomials.

${ }^{9}$ To be precise, for each new draw of shocks, we check whether the path of $\Psi_{L}$ converges to the stochastic steady state over the next 50 periods, assuming no further shocks occur. If this condition is not fulfilled, we draw new shocks and repeat the procedure.
} 
discards more than $10 \%$ of draws. Moreover, for both discarding and pruning, the plot of $\Psi_{l, t}$ is so fuzzy that it cannot be treated as an acceptable approximation of the penalty function.

\subsection{3rd order approximation}

Given the failures documented above, we move on to the 3rd order approximation. This option looks promising given the deterministic impulse responses presented in Figure 6 . For most variables, the responses are quite close to those obtained from the deterministic solution, even though the initial drop in the penalty function slope in reaction to LTV easing is clearly exaggerated.

We next turn to stochastic simulations. Again, we draw 1000 shocks to LTV and present the scatterplot of $\Psi_{l, t}$ (Figure 9 ). As becomes evident, this time the approximated shape of the penalty function derivative suffers from another weakness: it becomes negative for sufficiently low values of $\Gamma_{t}$. In other words, at low levels of leverage, the approximated slope of the penalty function again generates artificial incentives: it punishes impatient households for reducing their debt. Moreover, it is clear from Figure 9 that such episodes occur relatively frequently and hence cannot be ignored.

This problem becomes even more pronounced if we add the remaining two shocks to the model. As can be seen in Figure 10, now the left negative arm of the penalty function dominates the right one. Also, the image of the penalty function is no longer sharp, especially for low leverage. On the positive side, and in contrast to the 2nd order approximation, the negative slope of the penalty function makes the simulations more stable for low levels of debt as now impatient households are encouraged to increase it once it becomes sufficiently small. As a result, stochastic simulations with the 3rd order perturbation explode very rarely. It has to be borne in mind, however, that this stability is just a nice byproduct of twisted incentives.

\subsection{4th order approximation}

Finally, we turn to the 4th order approximation. In this case, the deterministic impulse responses to large LTV shocks (Figure 6) virtually coincide with those obtained with the 
non-approximated model. Again, we next run stochastic simulations, obtained as before, i.e. using 1000 draws for innovations in LTV. At first glance, the 4th order perturbation seems to be a clear improvement. The shape of $\Psi_{l, t}$ presented in Figure 11 looks very promising as it displays a clear asymmetry and is nearly flat for low values of $\Gamma_{t}$. Unfortunately, a deeper investigation reveals substantial shortcomings of this approximation. First, larger standard deviation of LTV shocks (1\%) move the left tail of the penalty function slope into regions where it becomes increasing in lower values of $\Gamma_{t}$. Second, and more worrying, if we add other shocks to the model (productivity or monetary), the model becomes highly unstable for reasons discussed while presenting the 2nd order approximation and related to an additional fixed point created by the left arm of $\Psi_{l, t}$. As a result, running stochastic simulations requires discarding a significant (over 15\%) proportion of draws. Also, the image of the penalty function (not shown) is even more fuzzy than that for the 3rd order approximation.

All in all, we have to report discontent with the feasible local approximations. The three perturbation orders we analyzed above suffer from several critical problems, related to the shape of the approximated penalty function derivative as well as from instabilities that prevent running simulations for realistic volatility of shocks. It has to be stressed that a further increase in the order of approximation not only does not guarantee success, but for models of reasonable size also becomes prohibitively expensive in terms of computing time.

\section{Robustness checks}

In order to confirm the robustness of our findings we conduct two important experiments. In the first one, we use our baseline model, but modify the functional form of the penalty function. In the second we retain the exponential penalty function but apply it to a somewhat different model. Given the multiplicity of these additional results, we do not replicate all the figures presented for our baseline variant, and confine ourselves to showing the main results and describing the findings.

Regarding the first experiment, we check whether using an alternative penalty function to (20) affects our results. Given its economic meaning, we are looking for a similarly shaped function, i.e. an increasing and convex one, relatively flat for low values of $\Gamma_{t}$ and increasing 
sharply once $\Gamma_{t}$ becomes close to zero. Our particular choice is inspired by Dewachter and Wouters (2014) who employ an inversed third order penalty function to model an equity constraint of financial intermediaries. Adjusting this concept to our needs, we substitute (20) with:

$$
\Psi_{t}=-\frac{\eta}{\Gamma_{t}^{3}}
$$

This function has the familiar hyperbolic shape with asymptotes for $\Gamma_{t} \rightarrow 0$ and $\Gamma_{t} \rightarrow$ $-\infty$. In order to make our experiment comparable to the baseline, we calibrate $\eta$ so as to match the same steady state LTV ratio of $74.2 \%$. Our experiments concentrate on stochastic simulations since this is the area where the exponential penalty function clearly failed. On Figures 12 - 14 we present the results of stochastic simulations based only on LTV shocks (with standard deviation set to 0.0045 as in our baseline model). Two conclusions stand out. First, the shapes of $\Psi_{l, t}$ are similar to those shown on Figures 7,9 and 11 plotted from our baseline model. The only exception is the one obtained for the second order approximation as it now does not have a left arm. However, to generate this chart more than $50 \%$ of draws had to be discarded due to instability and these were almost exclusively those that would make up the missing left arm. Overall, this robustness check suggests that what really matters is not the exact functional form of the penalty function, but rather the order of approximation and the respective polynomial that is used to approximate the function. As a result, the model suffers from similar problems as our baseline. Second, when all shocks are included the simulation results (not shown) are even more fuzzy and the number of rejected draws larger than in our baseline model.

In the second experiment we augment our baseline model for the presence of banks and place a penalty function in this area. Following Gerali et al. (2010), we introduce a simple model of banking with a capital requirement restricting the quantity of loans. In this model there are two types of banks: monopolistically competitive retail banks that provide loans to households subject to a collateral constraint, and perfectly competitive wholesale banks that obtain deposits from households and provide loans to retail banks.

Our original model is modified in the following way. Households face a binding collateral 
constraint, i.e. (7) holds with equality. Retail banks obtain funds from wholesale banks at the rate $R_{L b, t}$ (not $R_{t}$ as before), i.e. (15) has the following form

$$
R_{L, t}=\mu_{L} R_{L b, t}
$$

where $\mu_{L}$ is a markup resulting from imperfect competition in the retail banking sector. Wholesale banks accumulate bank capital $K_{b, t}$ from proceeds $J_{b, t}$ (originating in both wholesale and retail banks, as wholesale banks own retail banks)

$$
K_{b, t}=\left(1-\delta_{b}\right) K_{b, t-1}+\omega_{b} J_{b, t}
$$

where $\delta_{b}$ denotes the depreciation rate of the bank capital (which captures the use of resources in the banking activity). Additionally, a fraction $1-\omega_{b}$ of $J_{b, t}$ is paid to patient households as dividends.

Wholesale banks take deposits $D_{t}$ at the policy rate $R_{t}$ and use them (together with bank capital) to finance loans $L_{b, t}$ extended to retail banks at the rate $R_{L b, t}$

$$
L_{b, t}=D_{t}+K_{b, t}
$$

In this activity, they have to meet the capital requirement constraint, which in real terms takes the form

$$
v_{t} l_{b, t} \leq k_{b, t}
$$

where $v_{t}$ denotes the minmum capital requirement (bank capital to loans) ratio, $l_{b, t} \equiv L_{b, t} / P_{t}$ and $k_{b, t} \equiv K_{b, t} / P_{t}$. We introduce this captial requirement via the penalty fuction

$$
\psi_{t}=\frac{\iota_{1}}{\iota_{0}} \exp \left[-\iota_{0}\left(k_{b, t}-\nu_{t} l_{b, t}\right)\right]
$$

that affects the flow of funds in the banking sector so that $J_{b, t}$ accumulates according to the following equation

$$
J_{b, t+1}=R_{L b, t} L_{b, t}-R_{t}\left(L_{b, t}-K_{b, t}\right)-P_{t} \psi_{t}+R_{L, t} L_{t}-R_{L b, t} L_{t}
$$


The problem of the wholsale bank gives rise to the following first order contition

$$
R_{L b, t}=R_{t}-\psi_{l b, t}\left(l_{b, t}, k_{b, t}\right)
$$

where $\psi_{l b, t}$ is the derivative of $\psi_{t}$ with respect to $l_{b, t}$

$$
\psi_{l b, t}=\nu_{t} \iota_{1} \exp \left[-\iota_{0}\left(k_{b, t}-\nu_{t} l_{b, t}\right)\right]
$$

and can be interpreted as the spread between the policy rate $R_{t}$ and the rate $R_{L b, t}$ at which the wholesale bank lends to retail banks. This spread is hence determined by the slope of the penalty function that banks have to pay for violating the capital requirement.

As in the first experiment, we focus our attention on stochastic simulations. Our findings are similar to those described earlier - the shape of the penalty function may be lost in perturbations. ${ }^{10}$ Figures $15-17$ present the 2 nd, 3rd and 4th order approximation to the slope of the penalty function $\psi_{l b, t}$. Clearly the model suffers from similar problems as before. The second and fourth order approximations generate a U-shaped penalty function. Under the third order approximation the slope can become deeply negative, generating wrong incentives to banks (i.e. penalizing them for increasing their capital holdings).

\section{Conclusions}

In this paper we investigate whether the introduction of collateral constraints in the form of a penalty function can be used as a practical shortcut for generating plausible dynamics related to financial shocks. Our question arises from two observations. First, financial shocks affect the economy in an asymmetric and non-linear way. In particular, expansionary shocks tend to have less impact than contractionary shocks. Moreover, negative effects of financial shocks are much more pronounced and long-lasting during episodes of high financial stress than in

\footnotetext{
${ }^{10}$ Recall that for our baseline model LTV shocks were sufficient to demonstrate the properties of the approximated penalty function, while a full composition of shocks made the model highly unstable. When the penalty function is placed in the banking sector the model is generally more stable and solely applying LTV shocks is not sufficient to demonstrate the properties of the penalty function. For this reason, we move directly to using the complete structure of shocks (i.e. productivity, monetary and LTV) calibrated as described in Table 3 .
} 
normal times. Second, the emerging literature on occasionally binding constraints, while addressing these issues, tends to rely on inequality constraints that call for global solutions. These are time consuming for small models and impossible to apply for larger models used currently for policy analysis at central banks and academia. The penalty function approach could thus potentially constitute a useful shortcut, allowing for the application of local approximation methods, and hence incorporating nonlinearities and asymmetries in medium and large scale models.

Having constructed a dynamic stochastic general equilibrium model with standard real and nominal rigidities and credit constraints in form of a penalty function, we analyze the model's deterministic properties. We find that the model is able to produce reactions in line with the stylized facts described above. In particular, it generates moderate and symmetric reactions to small shocks. However, once the shock magnitude increases, the impulse responses of several variables tend to become asymmetric, with more pronounced reactions to shocks that tighten the constraint.

We then move to analyzing local approximations and find that these allow to generate similar reactions as in the deterministic solution. However, this finding is valid for orders of approximations higher than two. The second order approximation to the penalty function tends to generate spurious asymmetry and should, in our view, be avoided.

Finally, we attempt to investigate the stochastic properties of the locally approximated models. Here, our findings are less optimistic. First, even for small shocks, the second and third order approximations to the penalty function assume highly undesirable shapes for low levels of indebtness. The former implies ever increasing rewards from reducing debt, the latter artificially punishes the agents for deleveraging. In this respect, the fourth order approximation cuts off relatively well. However, in a richer stochastic environment even this approximation suffers from high instabilities that, to our knowledge, cannot be removed in a satisfactory way.

Our robustness checks confirm and extend these findings. For penalty functions it is ultimately the order of approximation that determines their shape, not only the original functional form. As a result, the model can often generate unwelcome behaviour, including instabilities. Even if the simulations are stable, one should carefully check whether simula- 
tions do not enter regions where the approximated penalty function is inconsistent with its assumed functional form. We show that for models with credit constraints this is a frequent case.

We conclude that, the penalty function approach is an attractive way of introducing financial frictions into non-stochastic models. Unfortunately, it fails to fulfill our expectations in a realistic stochastic setting, making its fully fledged application in business cycle and macroprudential policy analysis problematic.

\section{References}

Abo-Zaid, Salem (2012) 'Optimal long-run inflation with occasionally-binding financial constraints.' mimeo, Ben-Gurion University of the Negev

Adam, Klaus, and Roberto M. Billi (2006) 'Optimal monetary policy under commitment with a zero bound on nominal interest rates.' Journal of Money, Credit and Banking 38(7), 1877-1905

Adjemian, Stéphane, Houtan Bastani, Michel Juillard, Ferhat Mihoubi, George Perendia, Marco Ratto, and Sï¡œbastien Villemot (2011) 'Dynare: Reference manual, version 4.' Dynare Working Papers 1, CEPREMAP

Aliaga-Díaz, Roger, and María Pía Olivero (2012) 'Do bank capital requirements amplify business cycles? bridging the gap between theory and empirics.' Macroeconomic Dynamics 16(03), 358-395

Angeloni, Ignazio, and Ester Faia (2013) 'Capital regulation and monetary policy with fragile banks.' Journal of Monetary Economics 60(3), 311-324

Aruoba, S. Boragan, Jesus Fernandez-Villaverde, and Juan F. Rubio-Ramirez (2006) 'Comparing solution methods for dynamic equilibrium economies.' Journal of Economic Dynamics and Control 30(12), 2477-2508

Assenmacher-Wesche, Katrin, and Stefan Gerlach (2008) 'Monetary policy, asset prices and macroeconomic conditions: a panel-VAR study.' Research series 149, National Bank of Belgium

Brunnermeier, Markus K., and Yuliy Sannikov (2014) 'A macroeconomic model with a financial sector.' American Economic Review 104(2), 379-421 
Brzoza-Brzezina, Michał, and Krzysztof Makarski (2011) 'Credit crunch in a small open economy.' Journal of International Money and Finance 30(7), 1406-1428

Brzoza-Brzezina, Michał, Marcin Kolasa, and Krzysztof Makarski (2013) 'The anatomy of standard DSGE models with financial frictions.' Journal of Economic Dynamics and Control 37(1), 32-51

Carlstrom, Charles T., Timothy S. Fuerst, and Matthias Paustian (2010) 'Optimal monetary policy in a model with agency costs.' Journal of Money, Credit and Banking 42(s1), 37-70

Christiano, Lawrence J., and Jonas D. M. Fisher (2000) 'Algorithms for solving dynamic models with occasionally binding constraints.' Journal of Economic Dynamics and Control 24(8), 1179-1232

Christiano, Lawrence J., Martin Eichenbaum, and Charles L. Evans (2005) 'Nominal rigidities and the dynamic effects of a shock to monetary policy.' Journal of Political Economy $113(1), 1-45$

Cooley, Thomas F., and Edward C. Prescott (1995) 'Economic growth and business cycles.' In Frontiers of Business Cycle Research, ed. Thomas F. Cooley (Princeton University Press) chapter 1, pp. 1-38

Cúrdia, Vasco, and Michael Woodford (2008) 'Credit frictions and optimal monetary policy.' National Bank of Belgium Working Paper 146, National Bank of Belgium

De Fiore, Fiorella, and Oreste Tristani (2013) 'Optimal monetary policy in a model of the credit channel.' Economic Journal 123(571), 906-931

De Wind, Joris (2008) 'Punishment functions.' mimeo, University of Amsterdam

Den Haan, Wouter J., and Joris De Wind (2012) 'Non-linear and stable perturbation-based approximations.' Journal of Economic Dynamics and Control 36(10), 1477-1497

Dewachter, Hans, and Raf Wouters (2014) 'Endogenous risk in a DSGE model with capital-constrained financial intermediaries.' Journal of Economic Dynamics and Control 43(C), 241-268

Eggertsson, Gauti B., and Michael Woodford (2004) 'Policy options in a liquidity trap.' American Economic Review 94(2), 76-79

Fahr, Stephan, and Frank Smets (2010) 'Downward wage rigidities and optimal monetary policy in a monetary union.' Scandinavian Journal of Economics 112(4), 812-840 
Fernández-Villaverde, Jesús, Grey Gordon, Pablo A. Guerrón-Quintana, and Juan RubioRamírez (2012) 'Nonlinear adventures at the zero lower bound.' NBER Working Papers 18058, National Bureau of Economic Research, Inc

Gerali, Andrea, Stefano Neri, Luca Sessa, and Federico M. Signoretti (2010) 'Credit and banking in a DSGE model of the euro area.' Journal of Money, Credit and Banking 42(s1), 107-141

Gilchrist, Simon, and Egon Zakrajsek (2012) 'Credit spreads and business cycle fluctuations.' American Economic Review 102(4), 1692-1720

Gomes, Sandra, Pascal Jacquinot, and Massimiliano Pisani (2012) 'The EAGLE. A model for policy analysis of macroeconomic interdependence in the euro area.' Economic Modelling $29(5), 1686-1714$

Grabek, Grzegorz, Bohdan Klos, and Grzegorz Koloch (2011) 'Skew-normal shocks in the linear state space form DSGE model.' NBP Working Papers 101, National Bank of Poland

Guerrieri, Luca, and Matteo Iacoviello (2015) 'OccBin: A Toolkit for Solving Dynamic Models With Occasionally Binding Constraints Easily.' Journal of Monetary Economics $70,22-38$

Hubrich, Kirstin, and Robert J. Tetlow (2012) 'Financial stress and economic dynamics: The transmission of crises.' Finance and Economics Discussion Series 2012-82, Board of Governors of the Federal Reserve System (U.S.)

Iacoviello, Matteo (2005) 'House prices, borrowing constraints, and monetary policy in the business cycle.' American Economic Review 95(3), 739-764

Iacoviello, Matteo, and Stefano Neri (2010) 'Housing market spillovers: Evidence from an estimated DSGE model.' American Economic Journal: Macroeconomics 2(2), 125-64

Judd, Kenneth L. (1998) Numerical Methods in Economics MIT Press Books (The MIT Press)

Kaufmann, Sylvia, and Maria Teresa Valderrama (2010) 'The role of credit aggregates and asset prices in the transmission mechanism: A comparison between the euro area and the USA.' Manchester School 78(4), 345-377

Kim, Jinill, and Francisco J. Ruge-Murcia (2009) 'How much inflation is necessary to grease the wheels?' Journal of Monetary Economics 56(3), 365-377 
Kim, Jinill, Sunghyun Kim, Ernst Schaumburg, and Christopher A. Sims (2008) 'Calculating and using second-order accurate solutions of discrete time dynamic equilibrium models.' Journal of Economic Dynamics and Control 32(11), 3397-3414

Kim, Sunghyun Henry, Robert Kollmann, and Jinill Kim (2010) 'Solving the incomplete market model with aggregate uncertainty using a perturbation method.' Journal of Economic Dynamics and Control 34(1), 50-58

Kiyotaki, Nobuhiro, and John Moore (1997) 'Credit cycles.' Journal of Political Economy $105(2), 211-48$

Kolasa, Marcin, and Giovanni Lombardo (2014) 'Financial Frictions and Optimal Monetary Policy in an Open Economy.' International Journal of Central Banking 10(1), 43-94

Kose, M. Ayhan, Christopher Otrok, Raju Huidrom, and Thomas Helbling (2011) 'Do credit shocks matter? A global perspective.' European Economic Review 55(3), 340-353

Lombardo, Giovanni (2010) 'On approximating DSGE models by series expansions.' Working Paper Series 1264, European Central Bank, November

Luenberger, D. (1973) Introduction to Linear and Nonlinear Programming (Addison-Wesley)

Meh, Cïœesaire A., and Kevin Moran (2010) 'The role of bank capital in the propagation of shocks.' Journal of Economic Dynamics and Control 34(3), 555-576

Mendicino, Caterina (2012) 'On the amplification role of collateral constraints.' Economics Letters $117(2)$, 429-435

Mendoza, Enrique G. (2010) 'Sudden stops, financial crises, and leverage' American Economic Review 100(5), 1941-66

Preston, Bruce, and Mauro Roca (2007) 'Incomplete markets, heterogeneity and macroeconomic dynamics.' NBER Working Papers 13260, National Bureau of Economic Research, Inc

Rotemberg, Julio J., and Michael Woodford (1999) 'Interest rate rules in an estimated sticky price model.' In 'Monetary Policy Rules' NBER Chapters (National Bureau of Economic Research) pp. 57-126

Smets, Frank, and Rafael Wouters (2003) 'An estimated dynamic stochastic general equilibrium model of the euro area.' Journal of the European Economic Association 1(5), 11231175 
Smets, Frank, and Rafael Wouters (2007) 'Shocks and frictions in us business cycles: A bayesian DSGE approach.' American Economic Review 97(3), 586-606

Tchakarov, Ivan, Philippe D Karam, Tamim Bayoumi, Hamid Faruqee, Ben Hunt, Douglas Laxton, Jaewoo Lee, and Alessandro Rebucci (2004) 'GEM: A new international macroeconomic model.' IMF Occasional Papers 239, International Monetary Fund 


\section{Tables and figures}

Table 1: Skewness of main housing market variables

\begin{tabular}{cc}
\hline Variable & Skewness \\
\hline Real house price inflation & $-1.17^{* *}$ \\
Housing investment & $-0.48^{* *}$ \\
Housing stock & $-0.50^{* *}$ \\
Real mortgage loans & -0.05 \\
Real mortgage loans (growth rate) & $-0.30^{*}$ \\
\hline
\end{tabular}

Note: $* * *$ denote significance at the $5 \%$ and $1 \%$ level, respectively. Real house prices reflect the CPI deflated Case-Schiller index (Source: Standard\&Poors; 1q1987 - 3q2011). Housing investment is defined as real private residential investment (Source: BEA; 1q1950-4q2011). Housing stock stands for real private residential fixed assets (Source: BEA; 1950-2010). Real mortgage loans are CPI deflated home mortgages of households and non-profit organizations (Source: Board of Governors; 1q1952-3q2011). All variables are detrended with the Hodrick-Prescott filter.

Table 2: The steady state ratios

\begin{tabular}{cc}
\hline Steady state ratio & Value \\
\hline Housing investment share in GDP & $5.5 \%$ \\
Capital investment share in GDP & $16.9 \%$ \\
Mortgage loans to annual GDP & $57 \%$ \\
Hours & 0.32 \\
Spread (annualized) & $1.5 \mathrm{pp}$ \\
LTV & 0.75
\end{tabular}

Note: housing investment is defined as private residential investment (Source: BEA; 1q1950-4q2011). Capital investment reflects private and government nonresidential investment (Source: BEA; 1q1950-4q2011). Mortgage loans are for households and non-profit organizations (Source: Board of Governors; 1q1952-3q2011). Spread is calculated as the annualized difference between 30-year mortgage rates and yields on 30-year government bonds (Source: FRED; 1q1977-4q2011). LTV is the loan to price ratio for mortgage loans (Source: Federal Housing Finance Agency; 1963-2010). GDP is defined as a sum of private consumption, residential investment and nonresidential investment. 
Table 3: Calibrated parameters

\begin{tabular}{ccl}
\hline Parameter & Value & Description \\
\hline$\beta_{P}$ & 0.99 & Discount factor, patient HHs \\
$\beta_{I}$ & 0.985 & Discount factor, impatient HHs \\
$\delta_{k}$ & 0.02 & Physical capital depreciation rate \\
$\delta_{\chi}$ & 0.00875 & Housing stock depreciation rate \\
$\omega_{I}$ & 0.7 & Share of impatient HHs \\
$A_{\chi}$ & 1.35 & Weight on housing in utility function \\
$A_{n}$ & 400 & Weight on labor in utility function \\
$\sigma_{c}$ & 2 & Inverse of intertemporal elasticity of substitution in consumption \\
$\sigma_{\chi}$ & 2 & Inverse of intertemporal elasticity of substitution in housing \\
$\sigma_{n}$ & 2 & Inverse of Frisch elasticity of labor supply \\
$\xi_{c}$ & 0.7 & Degree of external habit formation in consumption \\
$\xi_{\chi}$ & 0.7 & Degree of external habit formation in housing \\
$\theta_{w}$ & 0.75 & Calvo probability for wages \\
$\zeta_{w}$ & 0.5 & Indexation parameter for wages \\
$\mu_{w}$ & 1.2 & Labor markup \\
$\mu_{n} /\left(\mu_{n}-1\right)$ & 6 & Elasticity of substitution between labor of patient and impatient HHs \\
& & \\
$\mu_{1}$ & 1.2 & Product markup \\
$\theta$ & 0.75 & Calvo probability for prices \\
$\zeta_{\alpha}$ & 0.5 & Indexation parameter for prices \\
$\alpha$ & 0.31 & Product elasticity with respect to capital \\
$\kappa_{k}$ & 5 & Capital investment adjustment cost \\
$\kappa_{\chi}$ & 5 & Housing investment adjustment cost \\
$\mu_{L}$ & 1.0038 & Loan markup \\
$m_{\chi}$ & 0.75 & Steady state LTV \\
$\eta$ & 50 & Curvature of penalty function \\
$\pi$ & 1.005 & Steady state inflation \\
$\gamma_{R}$ & 0.9 & Interest rate smoothing \\
$\gamma_{\pi}$ & 1.5 & Response to inflation \\
$\gamma_{y}$ & 0.5 & Response to GDP \\
$\rho_{z}$ & 0.95 & Productivity shock - persistence \\
$\sigma_{z}$ & 0.005 & Productivity shock - standard deviation \\
$\rho_{m}$ & 0.975 & LTV shock -persistence \\
$\sigma_{m}$ & 0.0045 & LTV shock - standard deviation \\
$\sigma_{R}$ & 0.001 & Monetary policy shock - standard deviation \\
\hline & & \\
& &
\end{tabular}


Figure 1: Responses to a standard LTV tightening: the role of impatient households' discount factor
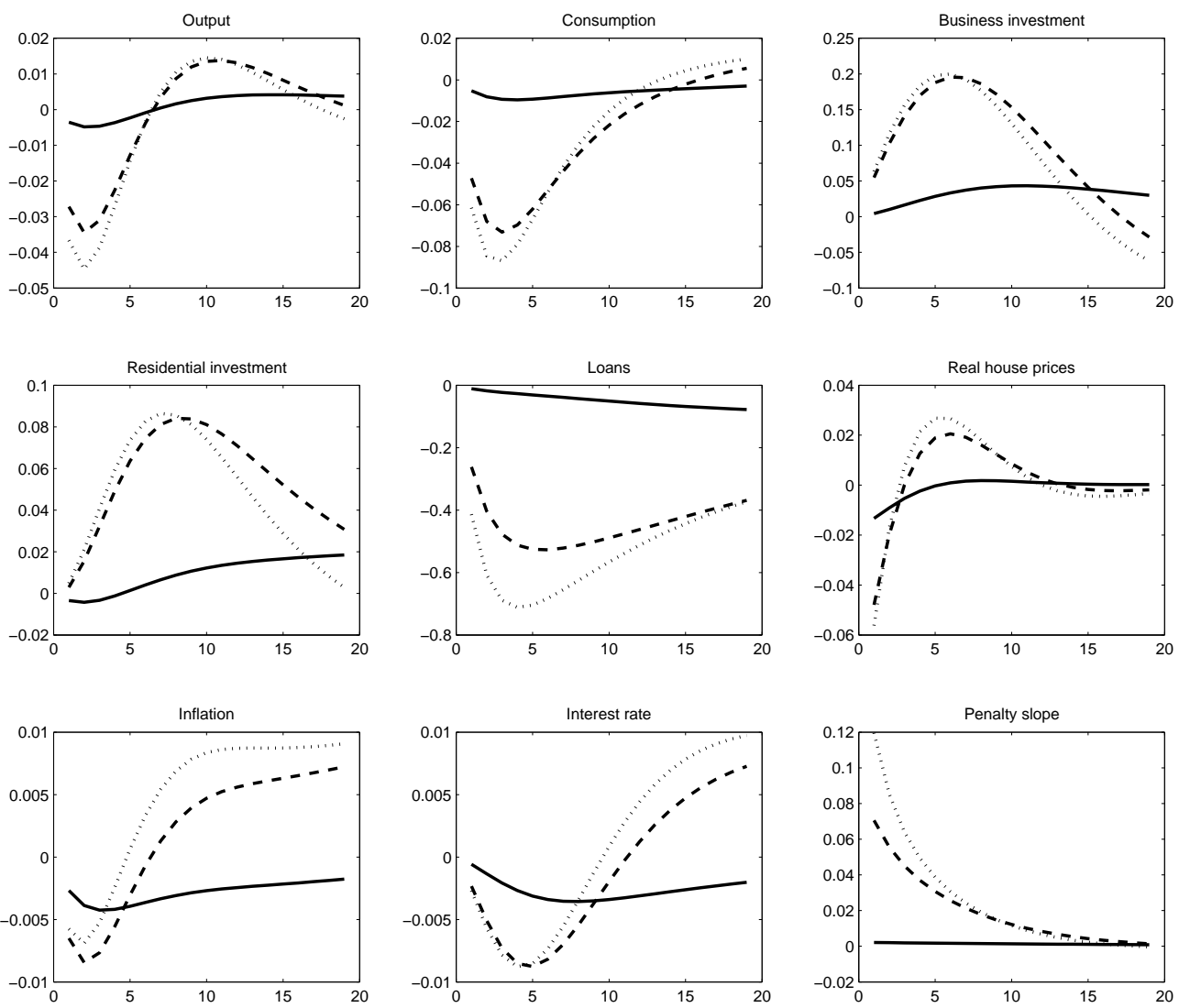

Note: Solid lines $-\beta_{I}=0.98622$, which implies the difference between its inverse and the steady state real interest on loans of $1 \mathrm{bp}$ (annualized); dashed lines - $\beta_{I}=0.985$ (baseline calibration, $50 \mathrm{bp}$ ); dotted lines - $\beta_{I}=0.98382$ (100 bp). 
Figure 2: Responses to a standard negative LTV shock: the role of penalty function curvature
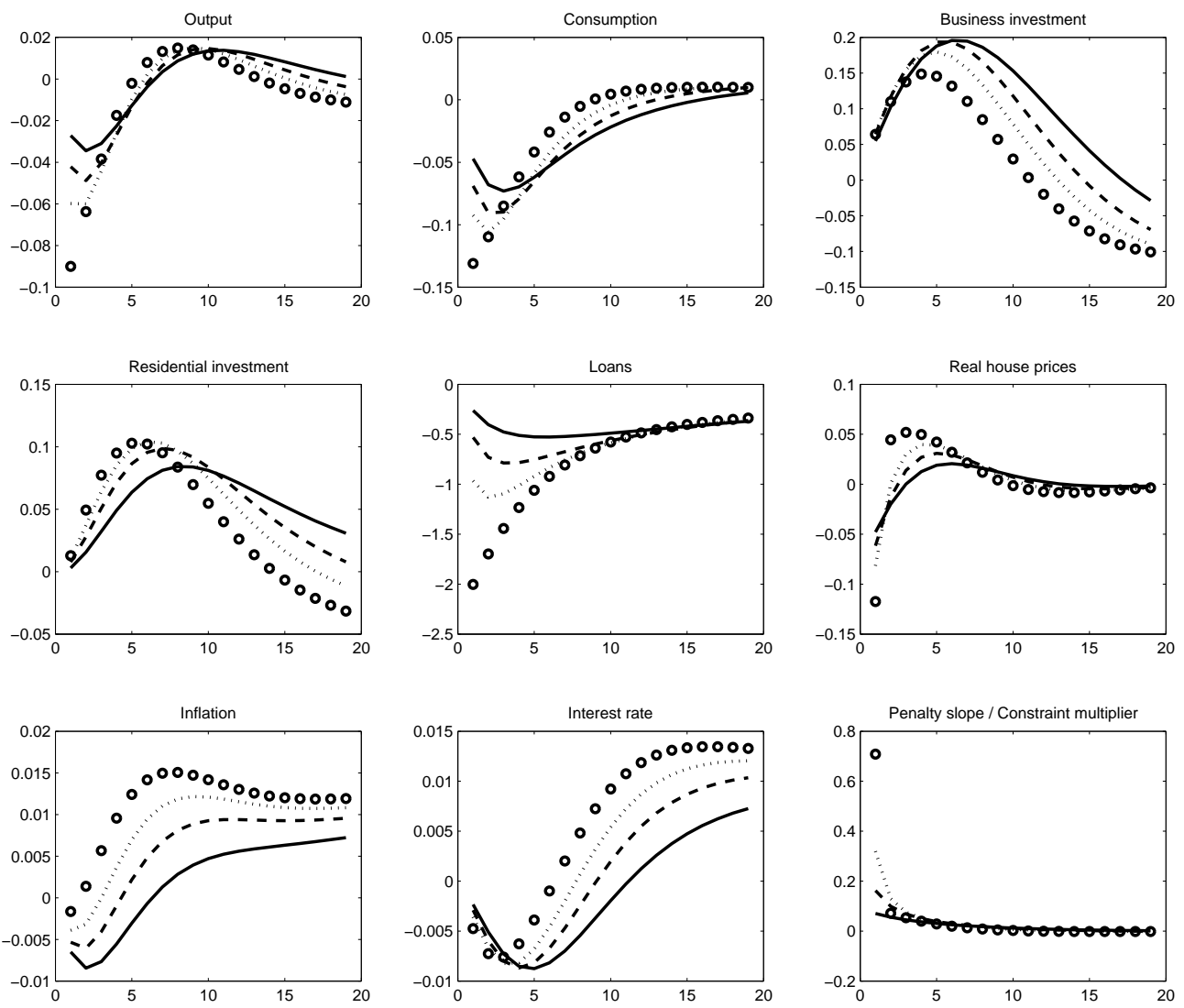

Note: Solid lines $-\eta=50$ (baseline calibration); dashed lines $-\eta=100$; dotted lines $-\eta=200$; circles $-\operatorname{EBC}(\eta \rightarrow \infty)$. 
Figure 3: Responses to positive and negative LTV shocks: small vs. large shocks
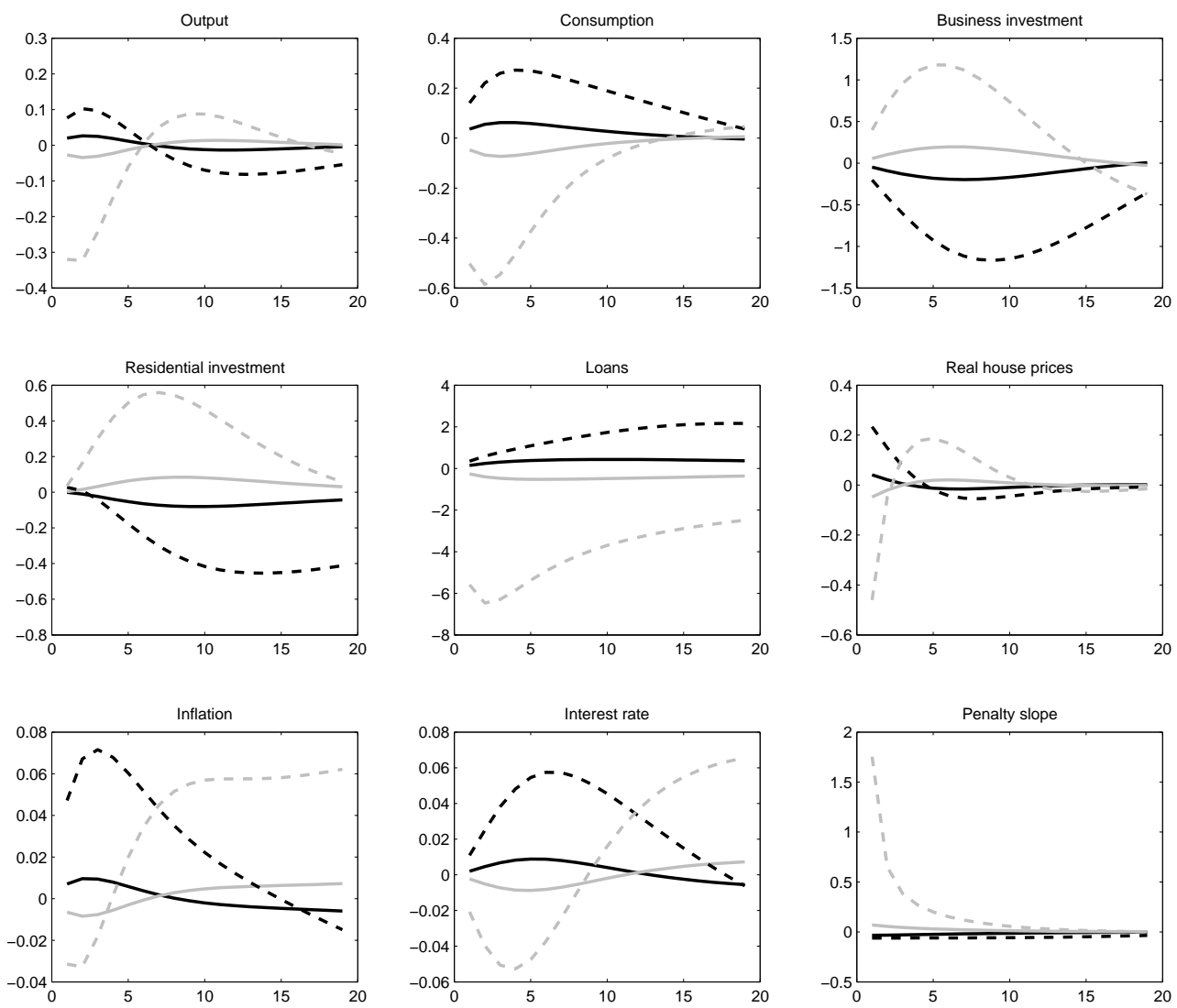

Note: Black solid lines - standard positive LTV shock (0.45\%); black dashed lines - big positive LTV shock (3\%); gray solid lines - standard negative LTV shock (-0.45\%); gray dashed lines - big negative LTV shock (-3\%). 
Figure 4: Responses to big positive and negative productivity shocks
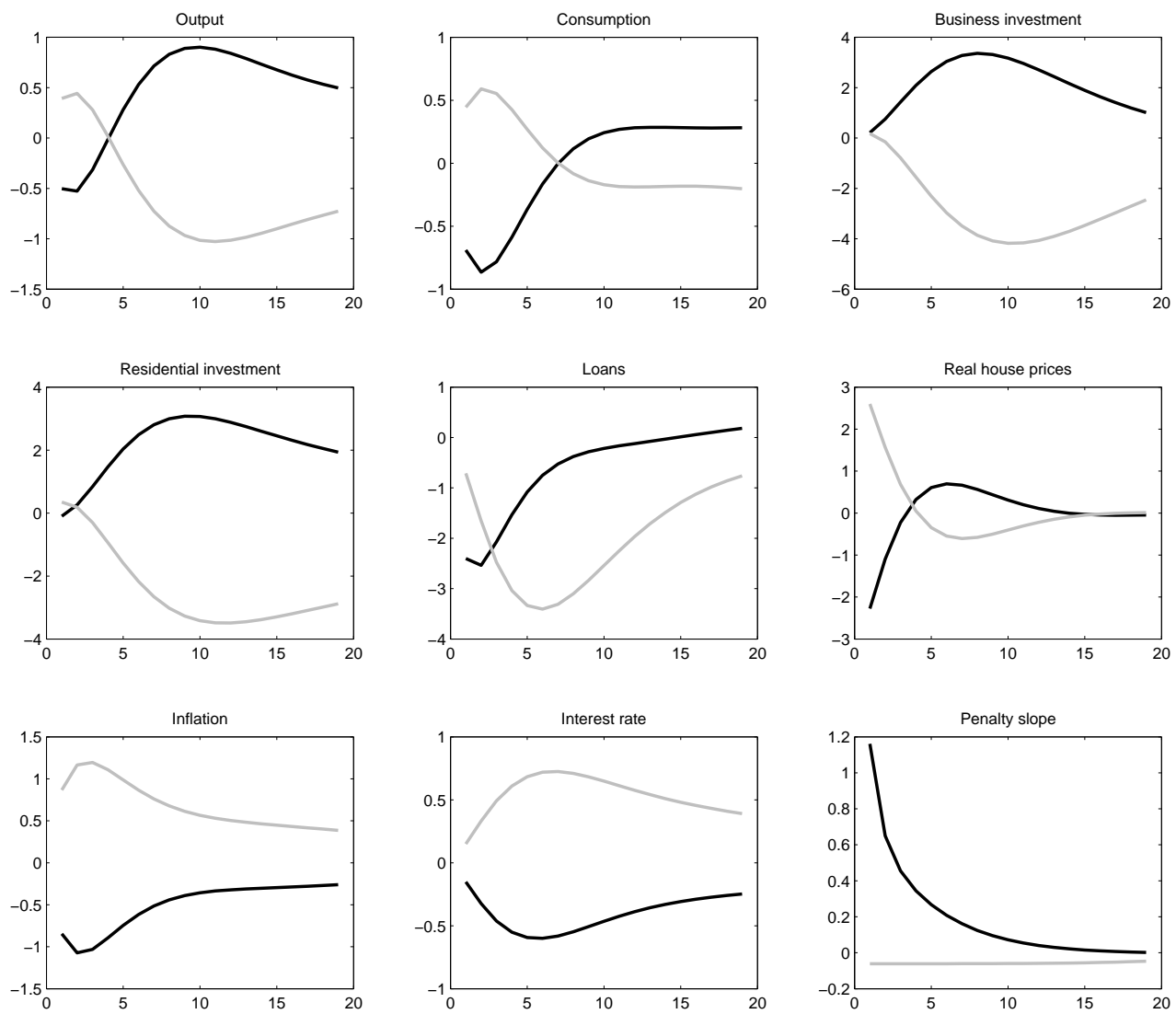

Note: Black lines - big positive productivity shock (1.5\%, i.e three standard deviations); gray lines - big negative productivity shock $(-1.5 \%)$. 
Figure 5: Responses to big positive and negative monetary shocks
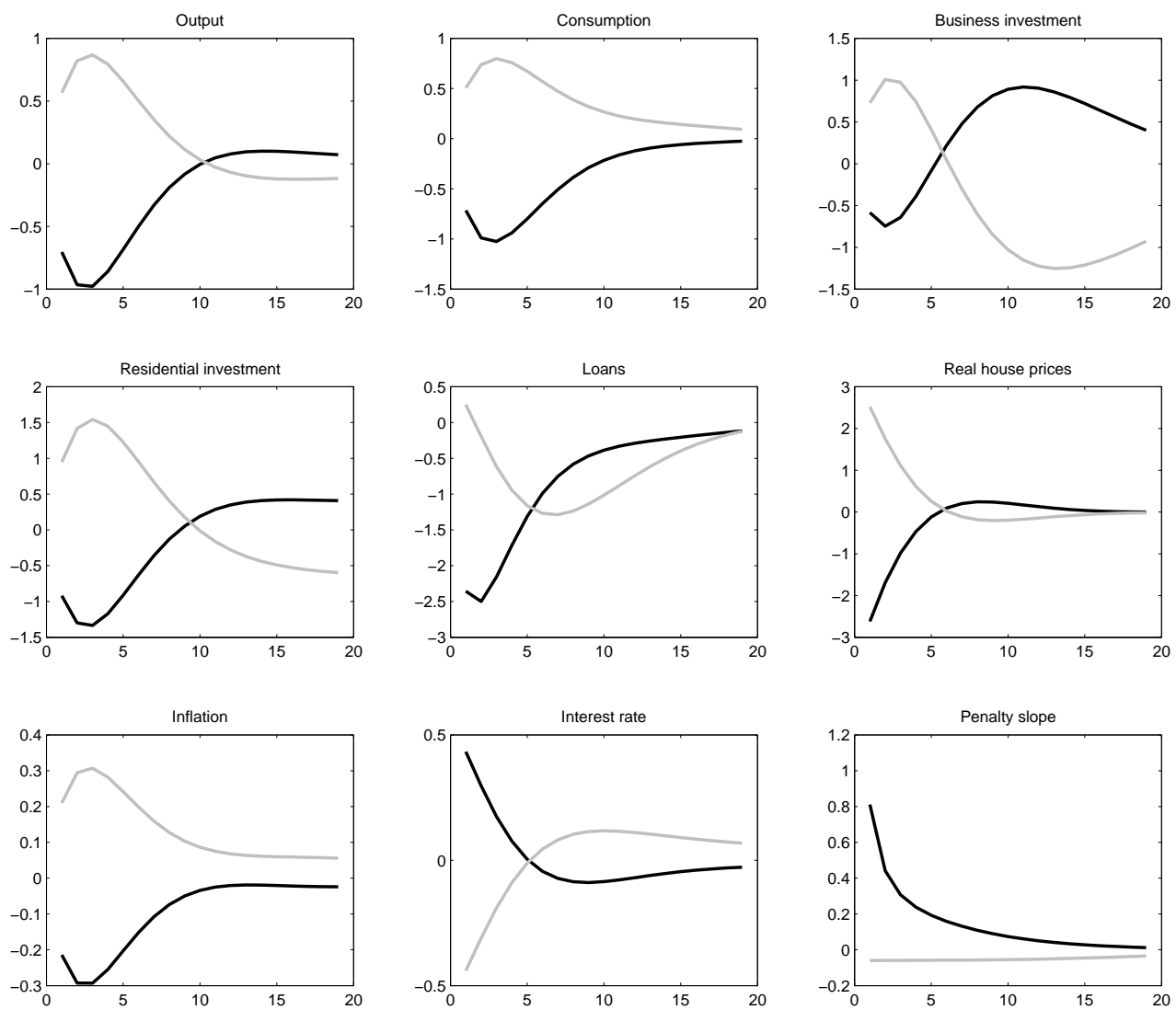

Note: Black lines - big positive monetary shock ( $2 \%$ annualized, i.e. five standard deviations); gray lines - big negative monetary shock (-2\% annualized). 
Figure 6: Impulse responses for the non-approximated and approximated models - big LTV shocks
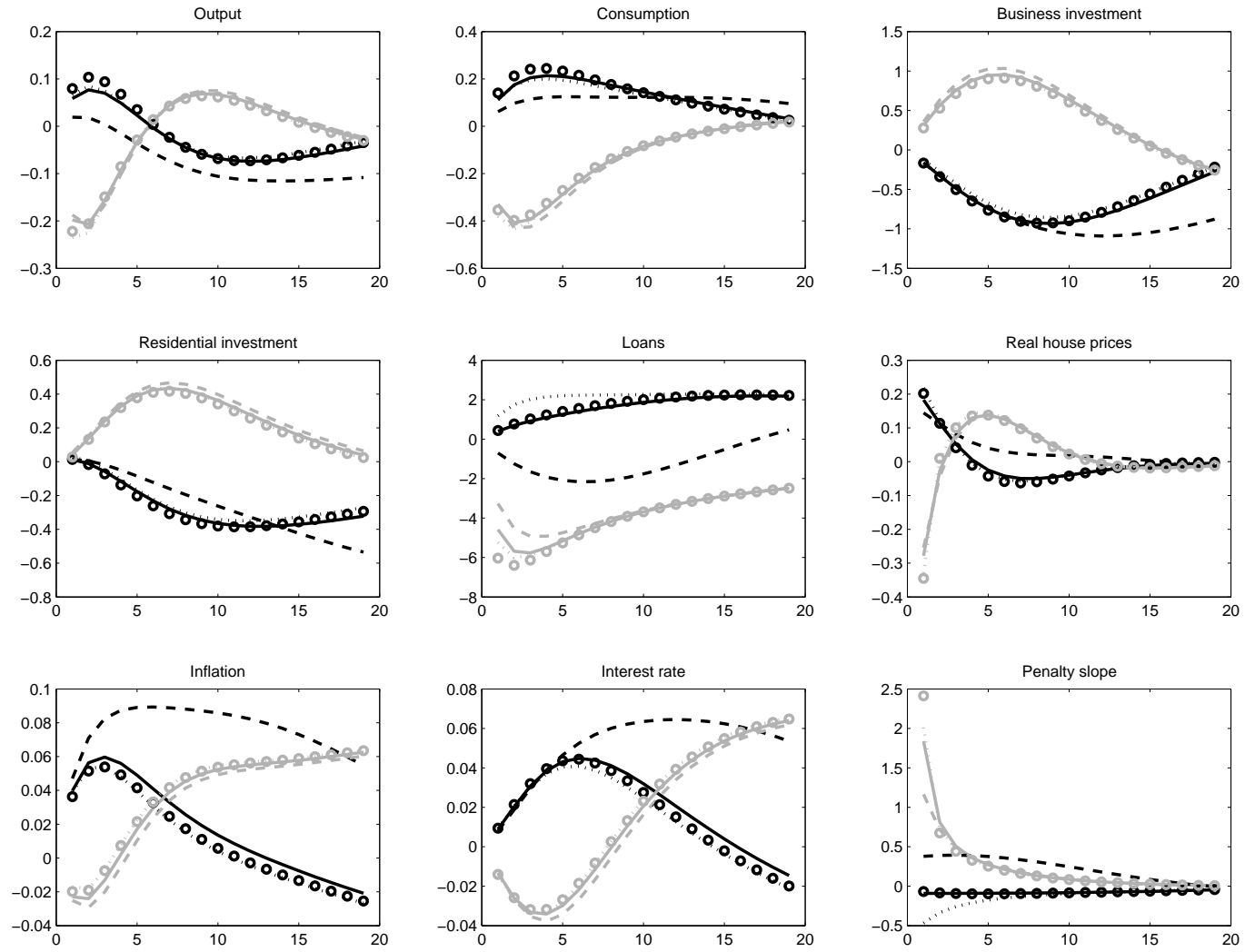

Note: Black lines - big positive LTV shock (3\%); gray lines - big negative LTV shock (-3\%); solid lines - non-approximated solution; dashed lines - 2nd order perturbation; dotted lines - 3rd order perturbation; circles - 4th order perturbation. 
Figure 7: Penalty function derivative - 2nd order approximation

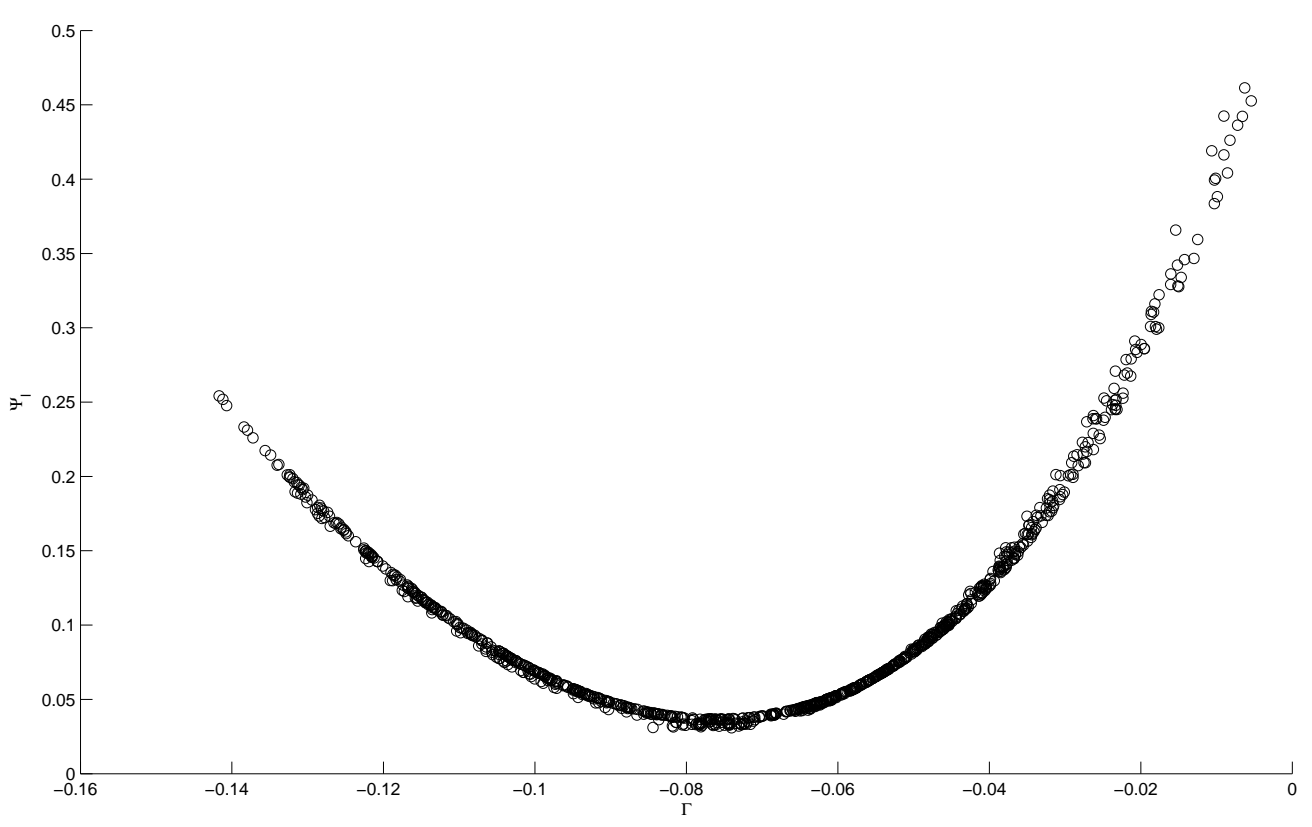

Note: The chart is based on stochastic simulations with LTV shocks.

Figure 8: Penalty function derivative under pruning - 2nd order approximation

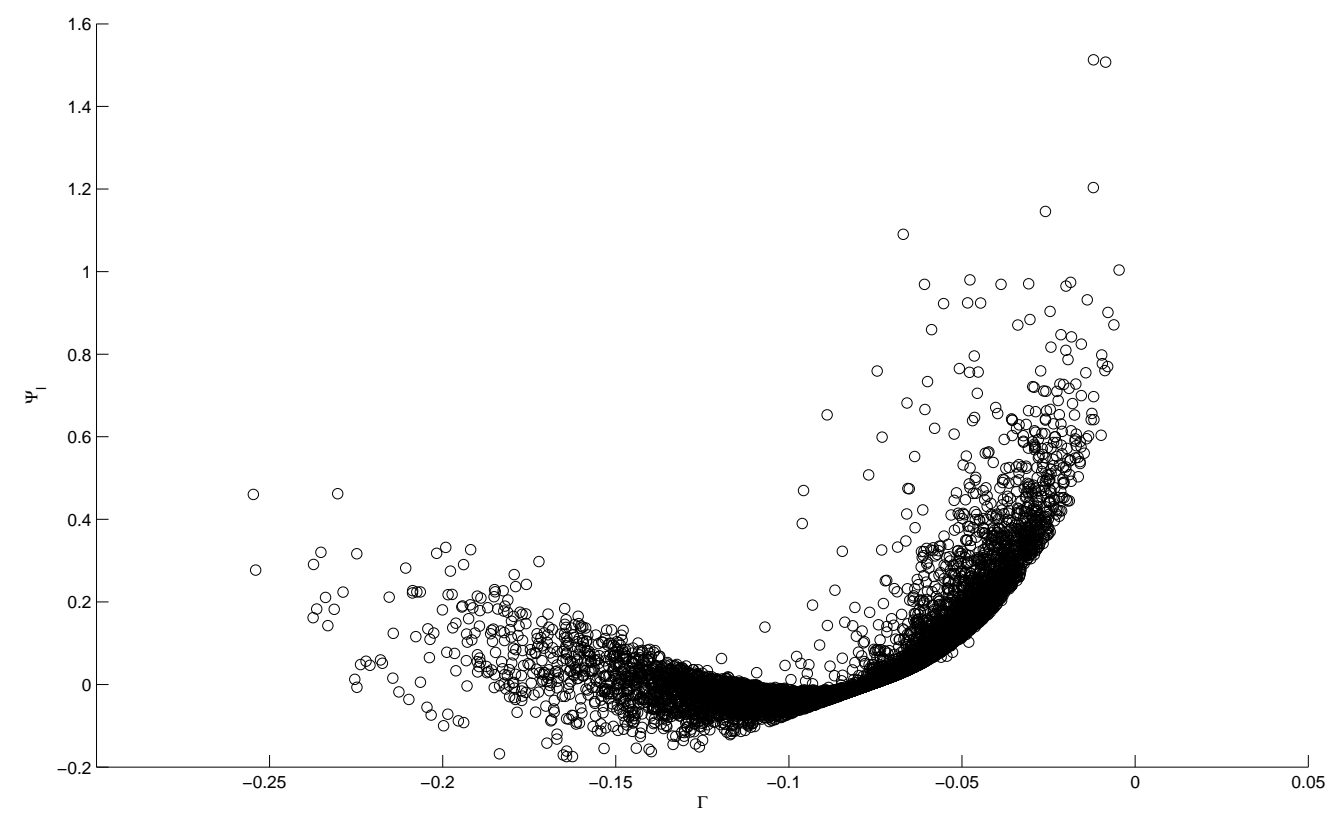

Note: The chart is based on stochastic simulations with LTV shocks. 
Figure 9: Penalty function derivative - 3rd order approximation

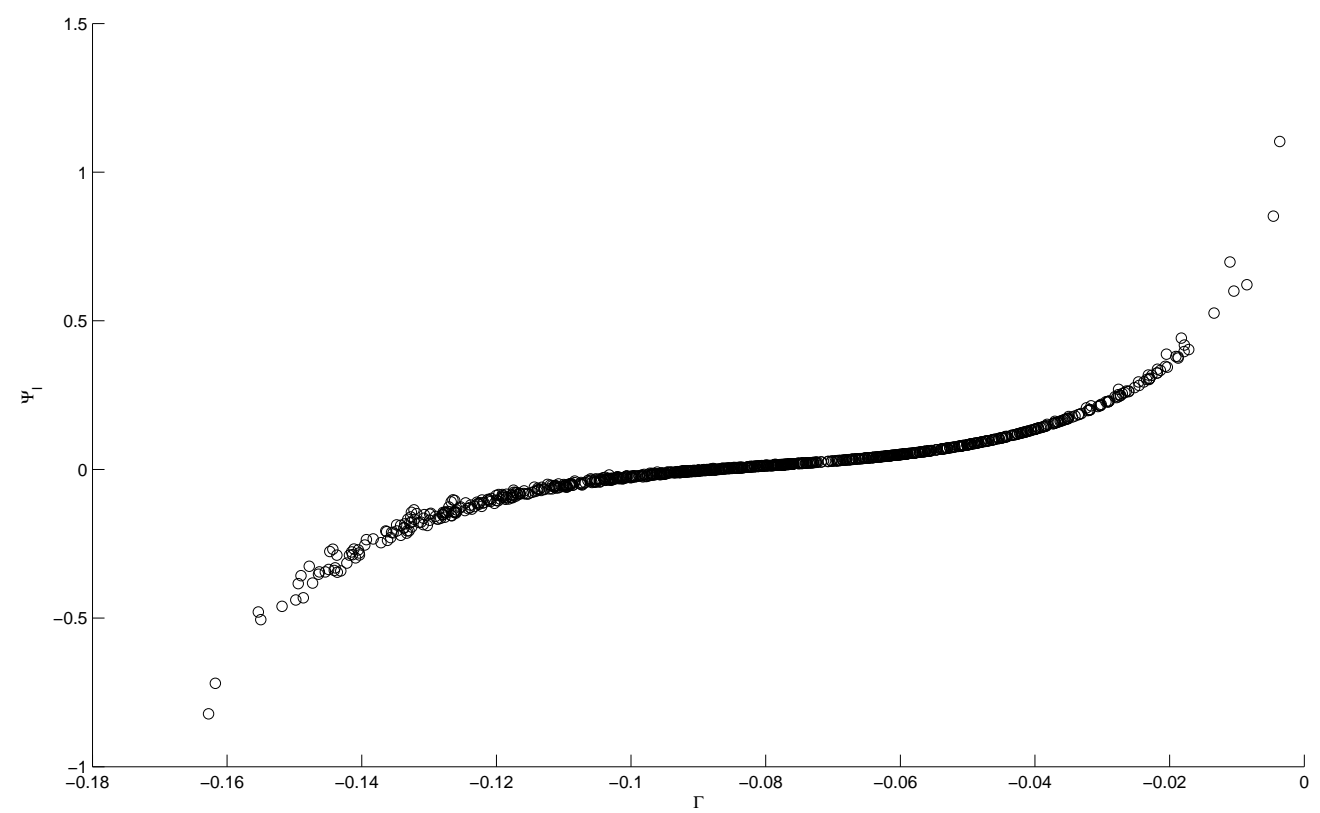

Note: The chart is based on stochastic simulations with LTV shocks.

Figure 10: Penalty function derivative - 3rd order approximation (all shocks)

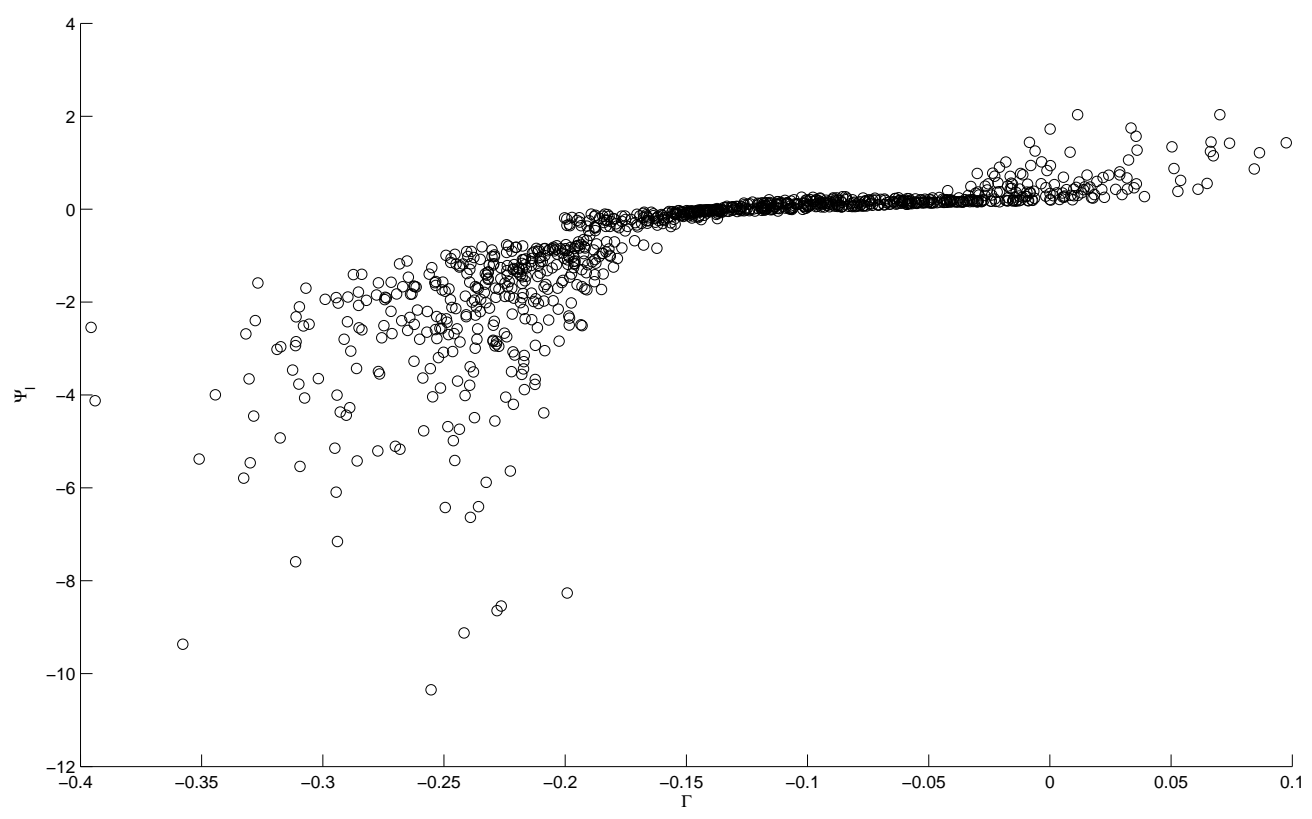

Note: The chart is based on stochastic simulations with LTV, productivity and monetary shocks. 
Figure 11: Penalty function derivative - 4th order approximation

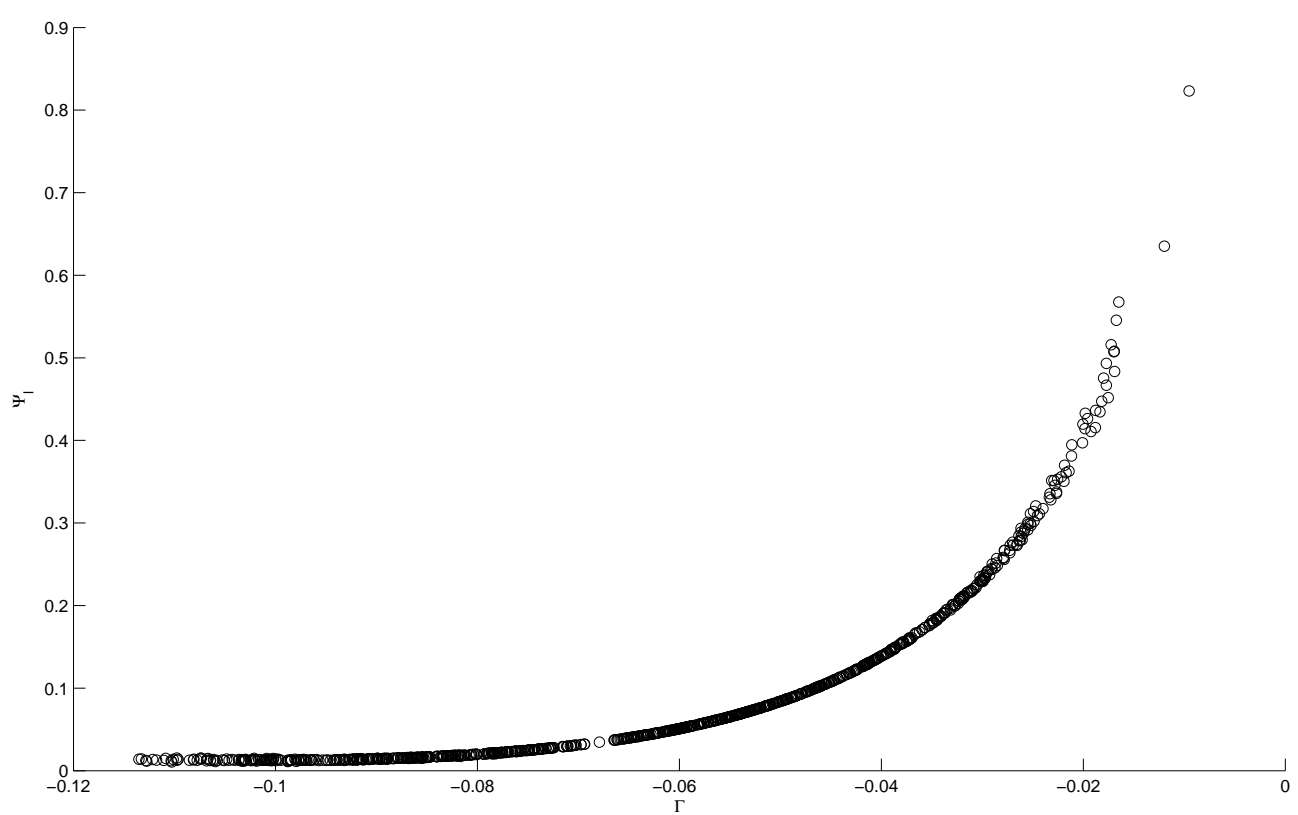

Note: The chart is based on stochastic simulations with LTV shocks.

Figure 12: Hyperbolic penalty function derivative - 2nd order approximation

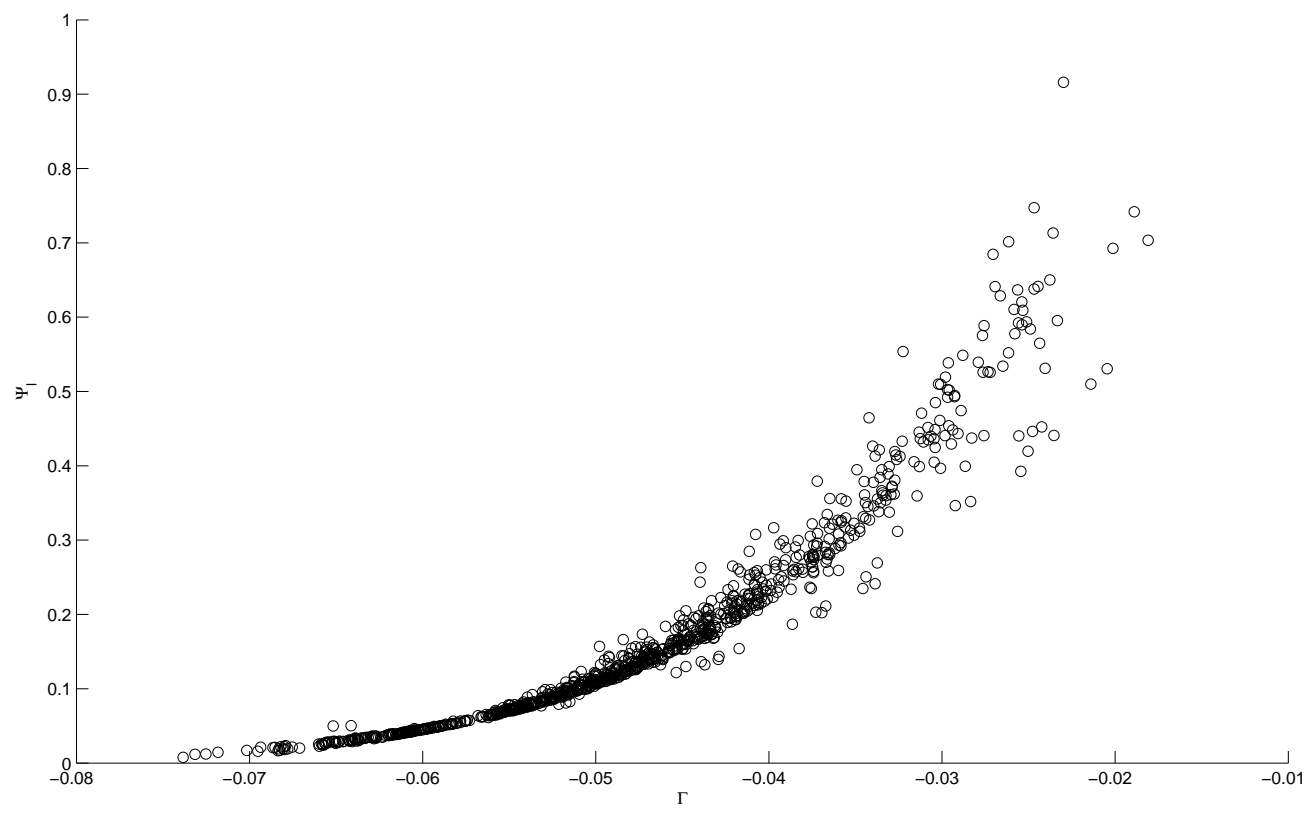

Note: The chart is based on stochastic simulations with LTV shocks. 
Figure 13: Hyperbolic penalty function derivative - 3rd order approximation

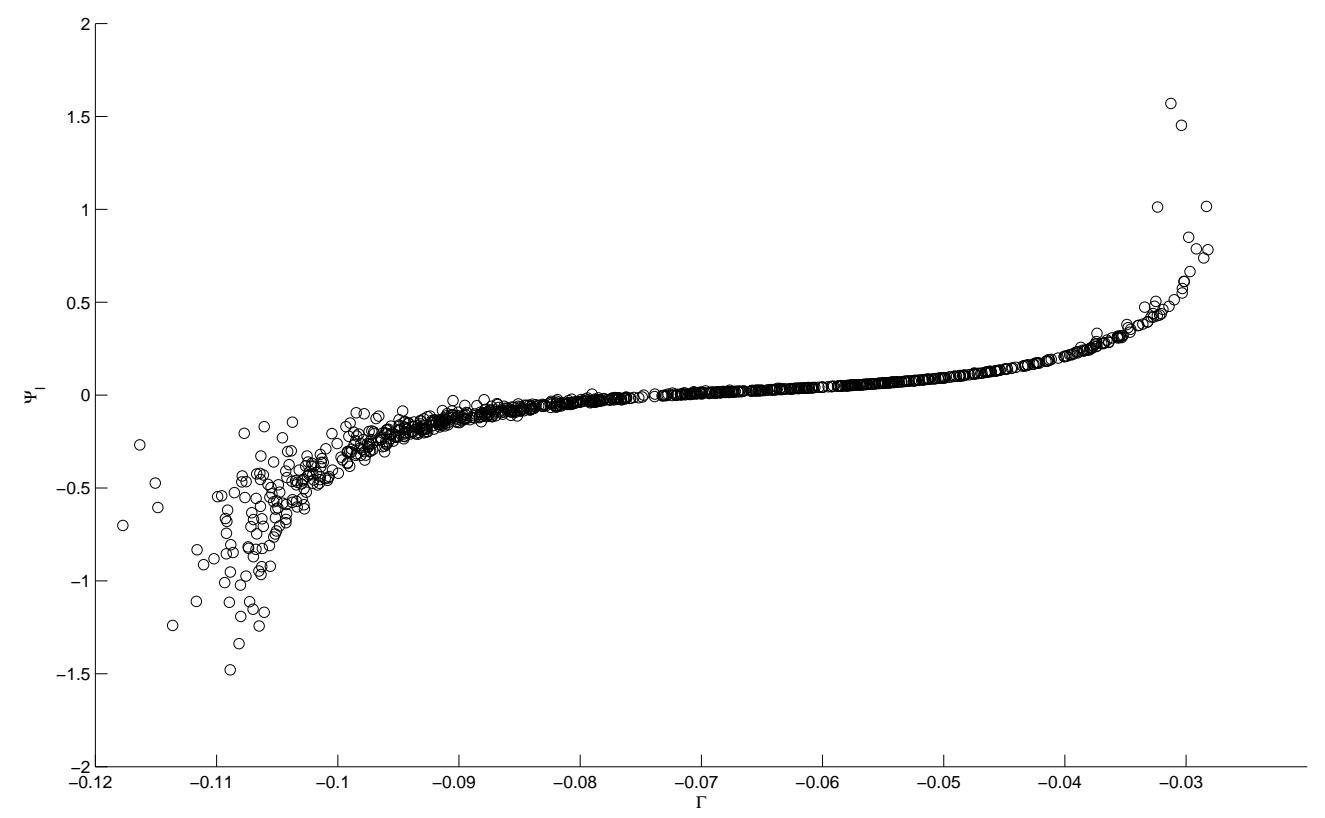

Note: The chart is based on stochastic simulations with LTV shocks.

Figure 14: Hyperbolic penalty function derivative - 4th order approximation

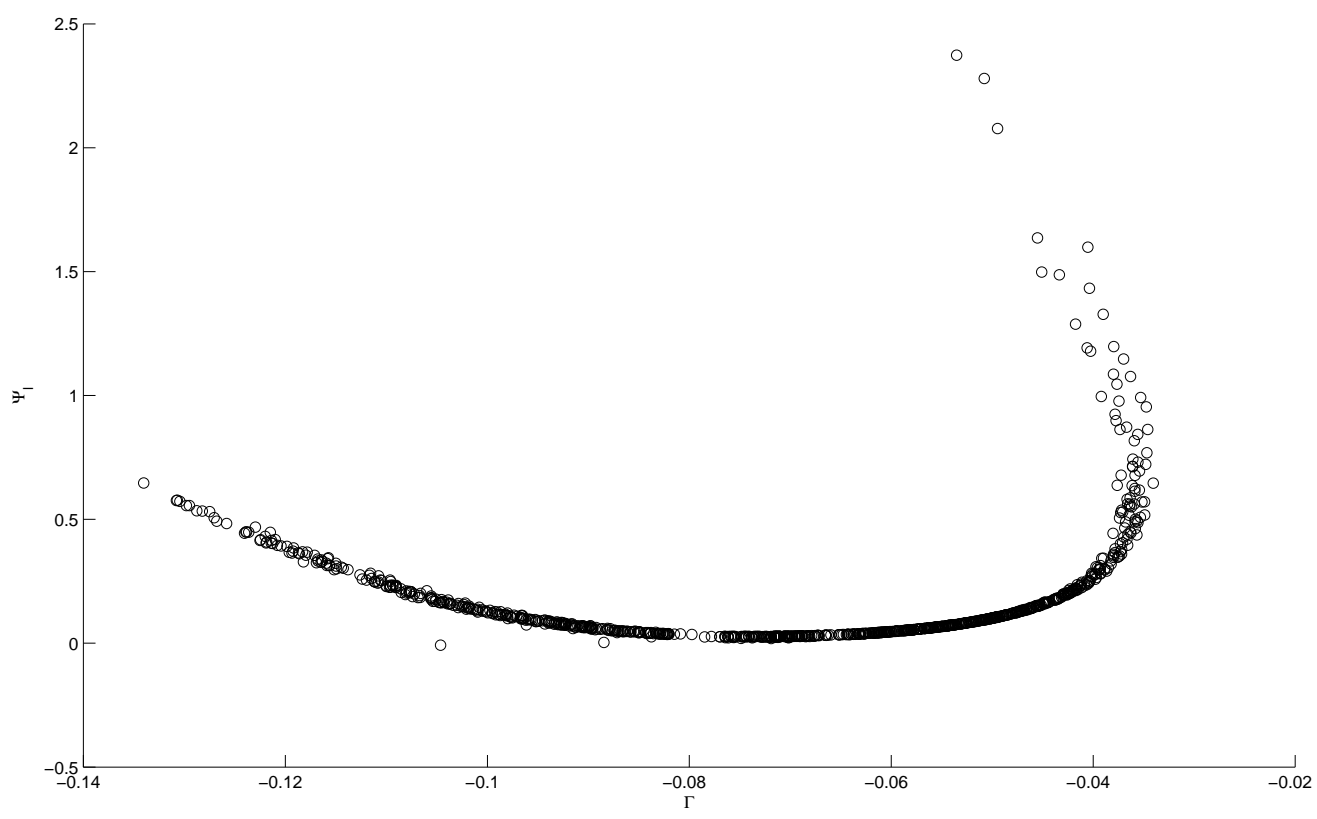

Note: The chart is based on stochastic simulations with LTV shocks. 
Figure 15: Penalty function in bank capital requirement - 2nd order approximation

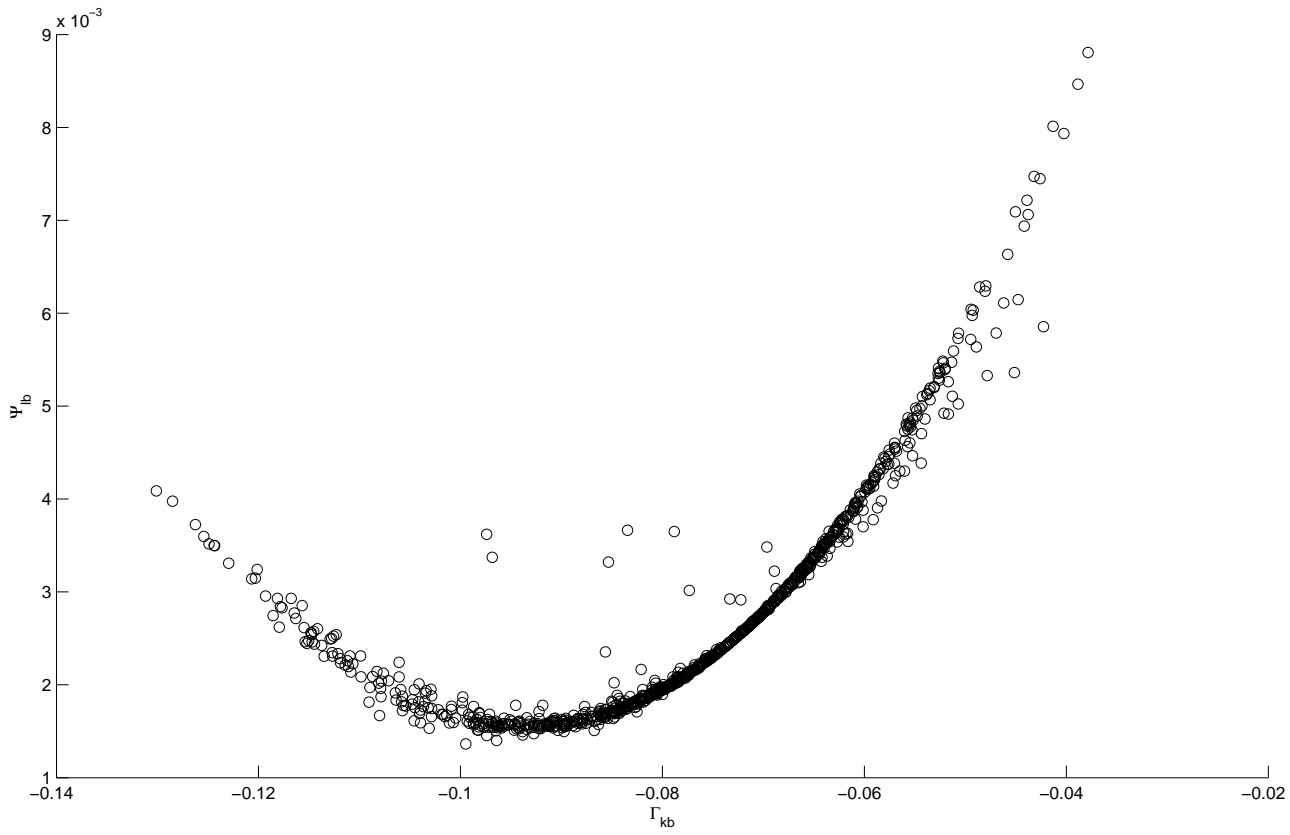

Note: The chart is based on stochastic simulations with all shocks.

Figure 16: Penalty function in bank capital requirement - 3rd order approximation

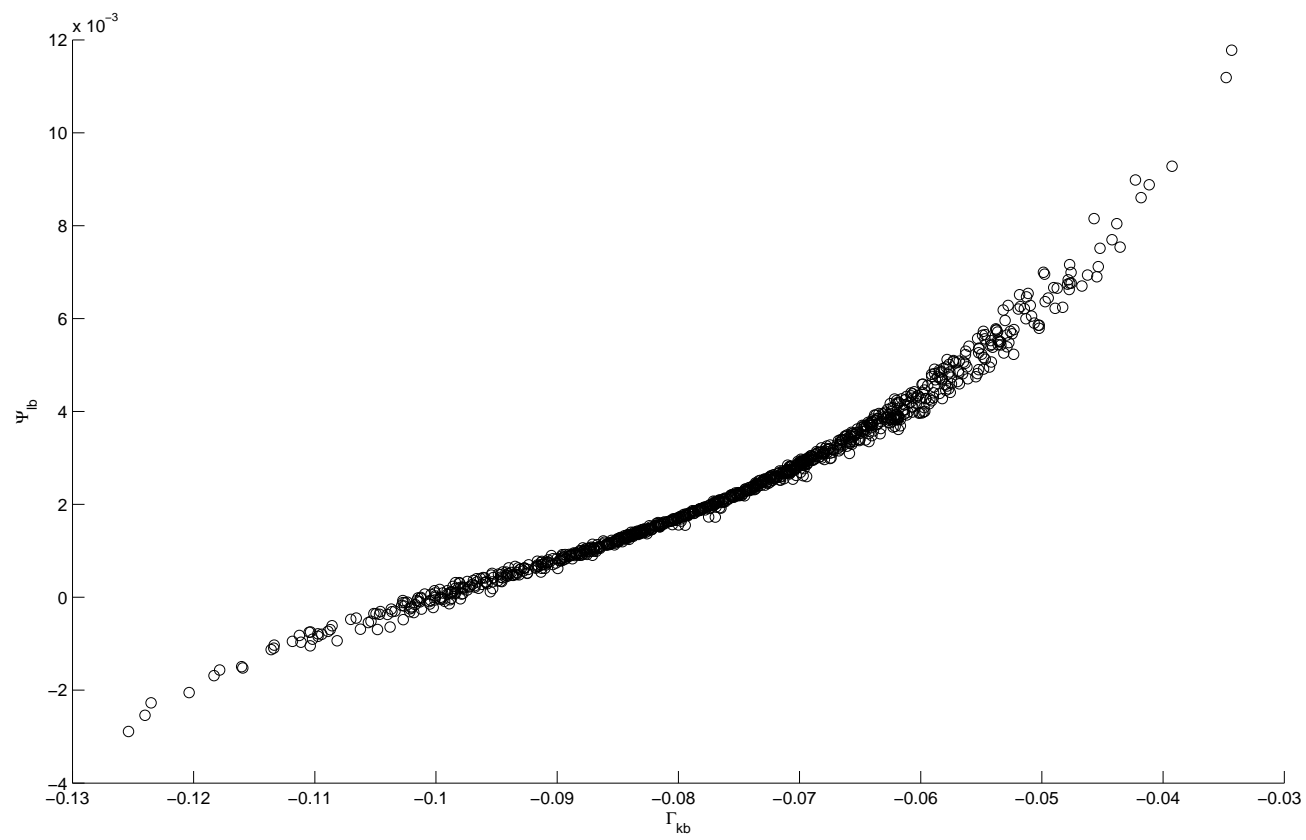

Note: The chart is based on stochastic simulations with all shocks. 
Figure 17: Penalty function in bank capital requirement - 4th order approximation

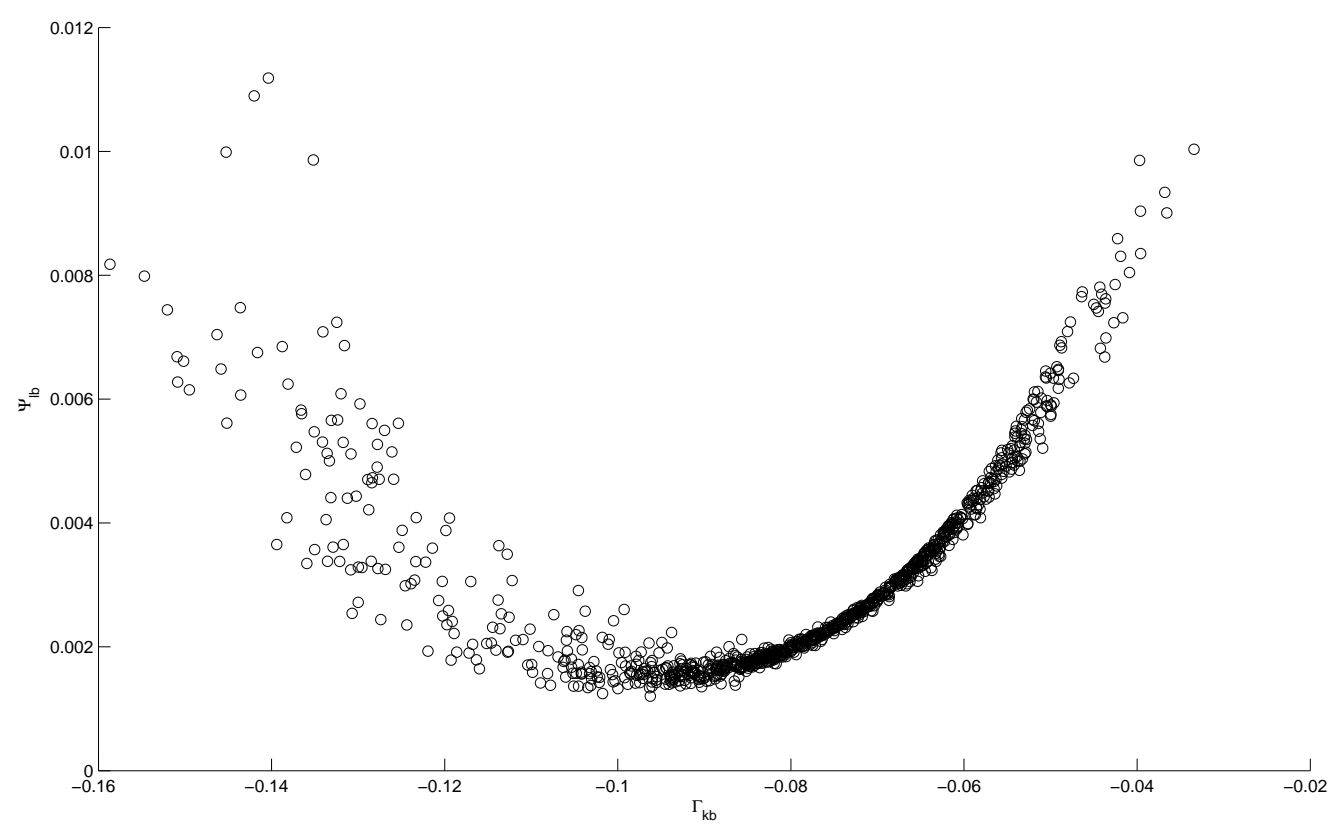

Note: The chart is based on stochastic simulations with all shocks. 